\title{
Der Drumlin von Hörmating in Oberbayern
}

\author{
Von Ingo Schaefer, München * \\ Mit 5 Abbildungen und 1 Tabelle
}

\begin{abstract}
$\mathrm{Zus}$ ammenf assung. Es wird der bislang vollständigste Einblick in die Schicht- und Lagerungsverhältnisse der Kiesgrube von Hörmating/Obb. geboten und dazu die Darstellung und Deutung durch Ebers (1960, 1963, 1965), Gross (1960), Kraus (1961) und Brunnacker (1962) kritisch beleuchtet.

Die beiden mächtigen fossilen Böden entstanden in keinem Falle in Interstadialabschnitten der Würmeiszeit („Göttweig“, „Paudorf“), sie gehören vielmehr in echte Interglazialzeiten, und zwar des p r ä rißeiszeitlichen Mittelpleistozäns 1 ).

A bst r a ct. A most detailed stratigraphic description of the gravel-pit of Hörmating/Bavaria is given and further a critical consideration of the interpretation of EBERs (1960, 1963, 1965), Gross (1960), Kraus (1961) and Brunnacker (1962).

The two thick fossil soils were both not formed in cool interstadial periods of Würm-ice-age ("Göttweig", "Paudorf"); they are both attributed to typical interglacial periods of prae-Riß middle-Pleistocaene.
\end{abstract}

\section{Vorbemerkungen}

Im Umkreis der Alpen findet sich eine riesige Zahl von geologischen Aufschlüssen, die Einblick in den Ablauf des Eiszeitalters bieten. Nach wie vor sind aber jene dünn gesät, die für sich allein sichere, allgemein gültige Aussagen erlauben. In der Regel ist das nur aus einer größeren, manchmal erst aus einer sehr großen Zahl von Aufschlüssen möglich ${ }^{2}$ ).

In den letzten Jahren schien aber einem in Oberbayern liegenden Aufschluß, der Kiesgrube von Hörmating, eine ganz besondere Bedeutung zuzukommen. So wurde es vor allem von Ebers (1960, 1963, 1965), Gross (1960), Kraus (1961), zum Teil auch von BRUNNACKER (1962) vertreten.

* Fern jedem Personenkult widme ich diese Arbeit Herrn Anton Micheler, der unter vielen bemerkenswerten Beobachtungen und Entdeckungen auch auf Hörmating gestoßen ist. Schon als junger Volksschullehrer galt seine ganze Freizeit der Natur seiner geliebten Heimat, und als Naturschutzbeauftragter von Oberbayern ging er darin fast völlig auf. In dieser Tätigkeit hat er sich vor allem der eiszeitlichen Erscheinungen angenommen, sie nach Möglichkeit geschützt und in einer großen Zahl von Publikationen einer weiteren Ơffentlichkeit nähergebracht. Dafür gebührt ihm der besondere Dank der Eiszeitforschung.

1) Hier - wie an weiteren Stellen des Textes — sprach ich vom Diluvium (bzw. Jung-, Mittel-, Altdiluvium). Die Schriftleitung hat mich angehalten, das durch „Pleistozän“ zu ersetzen. Ob allerdings die entsprechende Abmachung (des Internat. Geolog. Kongr. 1948 in London) in dieser strengen Art angewendet werden sollte, wage ich zu bezweifeln.

„Pleistozän“ ist ein erdgeschichtlicher Zeitabschnitt, der universelle Geltung haben muß; er kann daher weder durch stratigraphisch-tektonische, noch durch stratigraphisch-klimatische, sondern - wie alle anderen erdgeschichtlichen Zeitabschnitte - allein nach nicht umkehrbaren, nicht wiederholbaren stratigraphisch-paläontologischen Kriterien abgegrenzt werden. Das „Große Eiszeitalter" (= Diluvium) hingegen ist als ein klimatisches Phänomen - wie Albrecht Penck es getan hat - nur nach klimatischen Kriterien abgrenzbar. Wie die tektonische Phasengliederung hat die des "Großen Eiszeitalters" nur regionale Bedeutung. Darum erscheint mir die Gleichsetzung von Pleistozän = Großes Eiszeitalter nicht zwingend. (SChaEfEr 1951, S. 294/95).

2) So liegen, nur um das Maß der zwangsläufig notwendig gewordenen Verdichtung des Beobachtungsnetzes aufzuzeigen, meiner Arbeit über die donaueiszeitlichen Ablagerungen an Lech und Wertach (Geologica Bavarica 19/1953, S. 13-64) etwa 800 Aufschlüsse zugrunde, der über den Laufwechsel der Donau vom "Wellheimer Trockental“ ins "Neuburger Durchbruchstal“ (Mitt. Geogr. Ges. Mchn. 51/1966, S. "59-111) 278 Aufschlüsse und der Arbeit über die Räumung des Kirchener/Schmiech/Blau-Talzuges durch die Donau (Mitt. Geogr. Ges. Mchn. 52/1967, S. 191230) 284 Aufschlüsse. 
Wie verhält es sich damit?

Der Aufschluß liegt knapp $2 \mathrm{~km}$ westlich ${ }^{3}$ ) der Eisenbahnstation Ostermünchen (Strecke München-Rosenheim) und knapp $1 \mathrm{~km}$ nördlich des Wallfahrtsortes Tuntenhausen in einem Drumlin dicht südwestlich des Weilers Hörmating (Abb. 1).

„Entdeckt" wurde er am 24. 11. 1957 von Herrn Anton Micheler, damals Naturschutzbeauftragter von Oberbayern ${ }^{4}$ ). Mein erster Besuch fand gleich darauf am 3.12.1957 statt; dem folgten weitere 9 im Laufe der nächsten 10 Jahre. Rückschauend geurteilt, bot der Hörmatinger Aufschluß den besten und vollständigsten Einblick in den Jahren 1957 und 1958. Im Jahre 1959, als Ebers (1960) ihn kennenlernte, war das im nordwestlichen Teil nicht mehr der Fall. Im Jahre 1960 hat Kraus (1961) auch die von EBERs beschriebene Schichtenfolge des südöstlichen Teiles nicht mehr sehen können ${ }^{5}$ ), ebenso nicht im Jahre 1961 BRUNnACKer (1962); auch er muß sich hier auf die Darstellung von EBERS stützen ${ }^{6}$ ). Im Jahre 1962 sah EbERs (1963) noch die „kaffeebraune Verwitterungszone“, danach verschwand auch sie unter den Schuttmassen ${ }^{7}$ ).

Wenn ich nicht als erster zu Hörmating das Wort ergriffen habe, so lag das anfangs an meiner Scheu vor Parallelisierungen selbst noch so wichtig erscheinender Vorkommen über größere Räume hinweg; vor allem in den nach Untergrund und Deckschichten stark wechselnden Moränengebieten ist das immer ein gefährliches Unterfangen. Später war es die Hoffnung, daß mit fortschreitendem Abbau die Lagerungsverhältnisse der Jahre 1957 und 1958 wieder zutage kommen würden. Das ist aber in den vergangenen 10 Jahren leider nicht mehr eingetreten und - nach den derzeitigen Betriebsplänen - auch in $\mathrm{Zu}-$ kunft nicht zu erwarten. Da im Gegenteil Abbau und Verschüttung weiter zunehmen werden, sollte ich mit der Darstellung der - bislang besten - Aufschlußverhältnisse aus den Jahren 1957 und 1958 nicht länger zurückhalten. Dabei ist eine kritische Stellungnahme zu den inzwischen über den Hörmatinger Aufschluß erschienenen Abhandlungen nicht zu umgehen.

Zur besseren Lesbarkeit erscheinen im Haupttext nur die eigenen Beobachtungen, Feststellungen und Deutungen ${ }^{8}$ ); die der anderen Autoren werden jeweils in den Anmerkungen oder - bei längeren Ausführungen - in Kleindruckabschnitten behandelt.

3) so; südwestlich (EBERs 1960, S. 66) liegt er vom O r t Ostermünchen.

4) So auch bei Gross (1958, S. 156, Fußnote 1) erwähnt, wiewohl er später (1960, S. 100) die Entdeckung des Seekreide/Torfprofiles Ebers zuschreibt.

5) Kraus 1961, S. 50 („... konnte ich dieses tiefere Grubenprofil nicht so vollständig antreffen") sowie Abb. 4 ("der südliche Grubenteil hauptsächlich nach Angabe von E. EBERs"); entsprechend scheint sich der Hinweis "Aufnahme vom 17. 6. 1959" nicht auf seine Abb. 4, sondern auf die von Ebers (1960, Abb. 2) zu beziehen (siehe dazu auch Anmerkung 11).

6) Brunnacker 1962, S. 126 („Richtige Beobachtung des bei meinen Besuchen nicht mehr aufgeschlossenen Kontaktes... vorausgesetzt“), sowie Abb. 1 („seitlich nach den Angaben von E. Ebers (1960) ergänzt“).

7) Die Wiedergabe und Deutung des Hörmatinger Profils durch Gross (1960, S. 100) bleibt am besten außer acht, da er es anscheinend persönlich nicht kennengelernt hat. Die von ihm wiedergegebene und ausgewertete Schichtenfolge (Basalschotter - Seekreide und Torf - unterer Vorstoßschotter - Seeton - oberer Vorstoßschotter) entspricht nicht den Hörmatinger Befunden; sie weicht auch von der Darstellung bei EBers (1960, S. 67, Abb. 2) ab, auf die er sich beruft.

8) Aus Gründen der leichteren Verständlichkeit werden statt ungebräuchlicher und ungewöhnlicher oder sehr seltener Ausdrücke die allgemein üblichen verwendet, wie etwa orangefarben (statt kreßfarben), am Anfang oder in der Mitte (für proximal), am Ende (für distal); die Bedeutung von "Lassen" (EBERs 1960, S. 68) muß erraten werden, weil selbst in großen oder speziellen Nachschlagewerken nicht aufgeführt.

Ein neuerer bodenkundlicher Begriff — wie die „catena“" (EBERs, 1963, S. 88), jene von MiLne (1935) für die Tropen vorgeschlagene Bezeichnung einer sich öfter wiederholenden regelmäßigen Verteilung von Bodentypen in Abhängigkeit vom Relief (A. FincK: Tropische Böden, 1963, S. 80), sollte nur in diesem Sinne verwendet werden, also für Böden, die entwicklungsmäßig zusammengehören, nur reliefbedingte Unterschiede aufweisen. Bei dem von EbERs (1963, S. 88) nur einmal benutzten Begriff ("auch eine catena fehlt vollständig"), ist das nicht zu erkennen. 


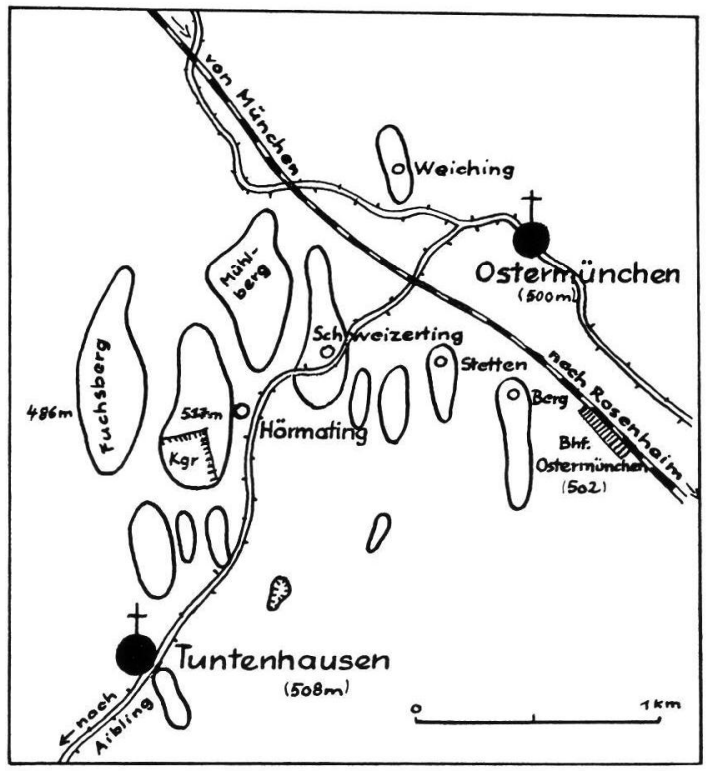

Abb. 1. Lageskizze der Hörmatinger Kiesgrube.

Bei meinen verschiedenen Arbeiten (der Freilegung, Aufschachtung, Geröllzählung, Einmessung) waren mir die Damen Dumpis und Mato, sowie die Herren Micheler und Zech behilflich; die bodenchemischen Analysen führte Herr Dr. WILD vom Bayer. Geolog. Landesamt durch, dessen Präsident, Herr Dr. Vidal, meiner entsprechenden Bitte in verständnisvoller Weise sofort stattgegeben hat; in gleicher Weise entgegenkommend war der Besitzer der Kiesgrube, Herr ScHMID, Tuntenhausen. Thnen allen gilt mein herzlicher Dank.

Die Behandlung von „Hörmating“ erfolgte im Rahmen einer längeren Untersuchungsreihe zu geologisch-geomorphologischen Fragen des Alpenvorlandes, bei der mir die Deutsche Forschungsgemeinschaft ihre stete Unterstützung hat zukommen lassen. Ihr spreche ich dafür auch an dieser Stelle meinen ganz besonderen Dank aus ${ }^{9}$ ).

\section{Beobachtungen und Feststellungen}

Der Aufschluß liegt inmitten eines aus etwa 14 Teilen bestehenden Drumlinkomplexes - mit Tuntenhausen an seiner SSW-Seite. Der Hörmatinger Drumlin selbst erreicht in S-N-Richtung eine Länge von etwa $800 \mathrm{~m}$ und in der O-W-Richtung eine Breite von etwa $300 \mathrm{~m}$. Der höchste Punkt hat knapp $518 \mathrm{~m}$ und findet sich — wie bei Drumlins üblich - auf der Eisströmungs-Luvseite, hier also im Süden. Die westlich benachbarte Talniederung ist ein Teil der von Penck (1901/09, S. 139) als "Glonn-Attel-Thalzug“ bezeichneten peripheren Gletscherschmelzwasser-Abflußrinne, die einen längeren Halt beim Eisrückzug markiert ${ }^{10}$ ). Sie hat hier etwa $486 \mathrm{~m} \mathrm{MH}$; der Höhenunterschied beträgt also maximal $32 \mathrm{~m}$.

Für eine richtige Deutung der in der Hörmatinger Kiesgrube nacheinander zutage getretenen Quartärschichten ist die jeweilige Richtung des Abbaues nicht unwichtig. 1957/58 erfolgte er in der Kiesgrube von $\mathrm{S}$ her; die bis etwa $300 \mathrm{~m}$ lange und bis über $20 \mathrm{~m}$ hohe Abbauwand verlief von $\mathrm{SO}$ in einem flach konkav geschwungenen Bogen über $\mathrm{N}$ nach SW. 1959 wurde der Abbau vornehmlich nach $\mathrm{O}$ und $\mathrm{N}$ getrieben, so daß sich zwei Kiesgrubenwände bildeten - eine in der Längsrichtung des Drumlins $(\mathrm{S}-\mathrm{N})$, die andere in

5) Neben den in Anm. 2) genannten Arbeiten von 1966 und 1967 war es vor allem die in den Jahren 1960-1966 erfolgte Fertigstellung der Kartierung des Gebietes des diluvialen Isar-Loisachgletschers im Maßstab 1:25000, die durch die Hilfe der Deutschen Forschungsgemeinschaft ermöglicht worden ist.

10) Näheres hierzu siehe bei Troll 1924, insbesondere in der zugehörigen Karte 1:100 000 . 
seiner Querrichtung (W-O) ${ }^{11}$ ). In den weiteren Jahren behielt man diese Abbauweise bei, nur wurde die S-N verlaufende Kiesgrubenwand durch Abraum und Abfall verschüttet und abgeböscht. Den heutigen und ehemaligen Zustand gibt Abb. 2 wieder.

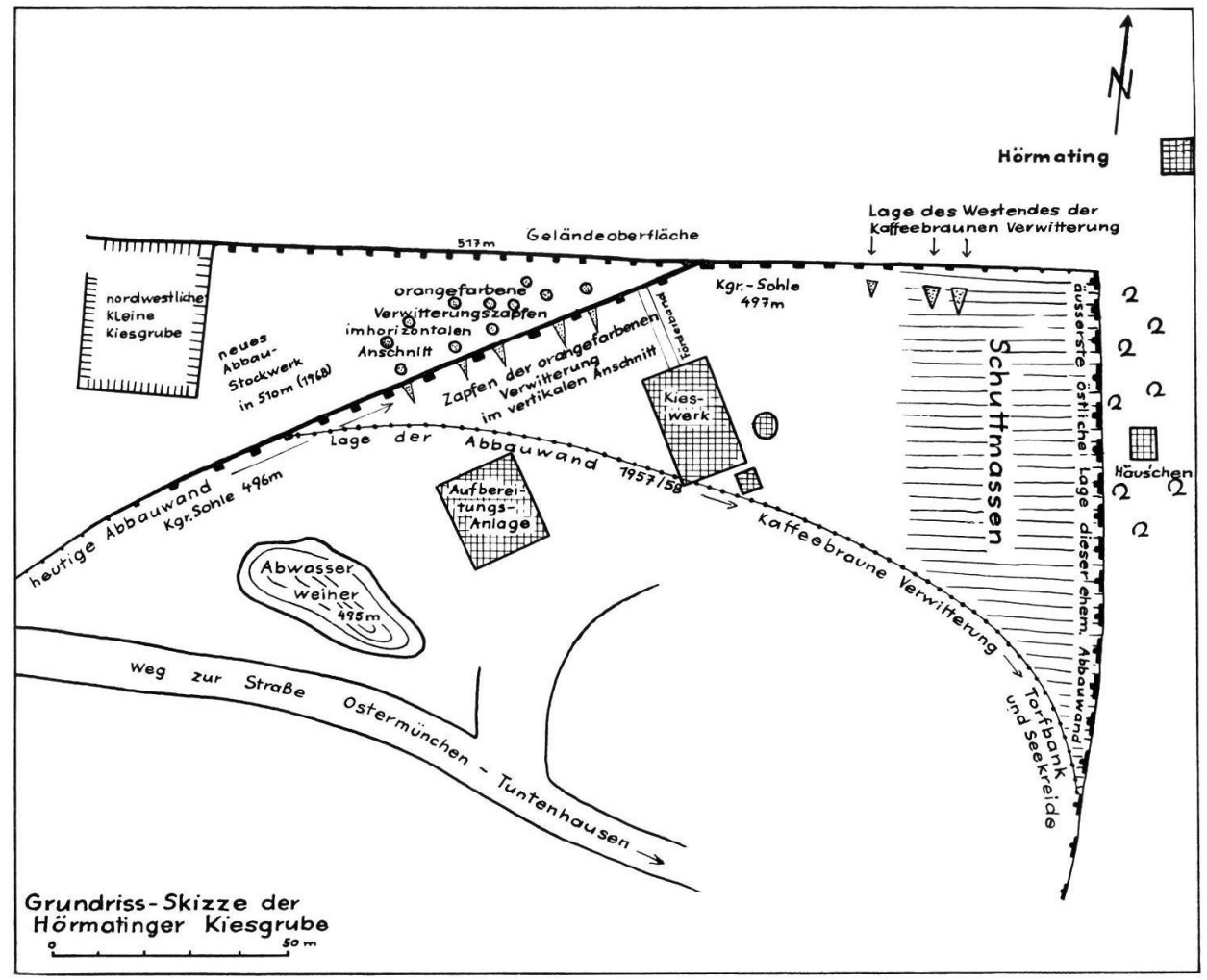

Abb. 2. Grundrißskizze der Hörmatinger Kiesgrube.

Die folgende Darstellung geht - wie gesagt — vornehmlich auf die guten Aufschlußverhältnisse der Jahre 1957/58 zurück. Für den mittleren Teil wurden noch die von 1959/63 herangezogen, als die hier auftretende kaffeebraune Verwitterungsrinde sichtbar war. Jetzt ist auch sie verschüttet; um Bodenproben zu entnehmen, konnte sie aber im - erbst 1967 an ihrem nördlichen Ende - im NO-Eck der heutigen Kiesgrube - auf fast $7 \mathrm{~m}$ Länge freigelegt werden. Das war im südöstlichen Teil der Kiesgrube, wo seinerzeit d'e See- und Torfablagerungen zum Vorschein kamen, nicht mehr möglich, - die Verschüttung ist hier zu stark; eine Freilegung erscheint an dieser Stelle aber nicht mehr notwendig, da die Lagerungsverhältnisse damals ziemlich genau erkannt werden konnten.

1. Der Schichtenaufbau im rechten (südöstlichen) Drittel der Abbauwand (Abb. 3).

Dieser Teil ${ }^{12}$ ) verlief seinerzeit zusammen mit dem mittleren Aufschlußteil in einer schwach gebogenen Flucht von SO nach NW, später von S nach N.

11) So auch bei Ebers (1960, S. 67 und 69) mit etwa $150 \mathrm{~m}$ für die Längsrichtung und etwa $130 \mathrm{~m}$ für die Querrichtung. Kraus (1961, S. 48, Abb. 4) und Brunnacker (1962, S. 126, Abb. 1) lassen die Querseite von NW nach SO verlaufen. Der erste mit Aufnahme vom 17. 6. 1959, also zus dem gleichen Sommer, in dem Ebers W-O-Richtung anzeigt (siehe dazu Anmerkung 5); Drunnacker's Angaben stammen von 1961.

12) Bei Ebers (1960, S. 68) der etwa 50 m lange Südabschnitt des S-N verlaufenden Längsprofils; in ihrer Abb. 2 das rechte Drittel. 
Höhe: bis 18 m; Grubensohle etwa 498 m, Gruben-Oberkante etwa 516 m.

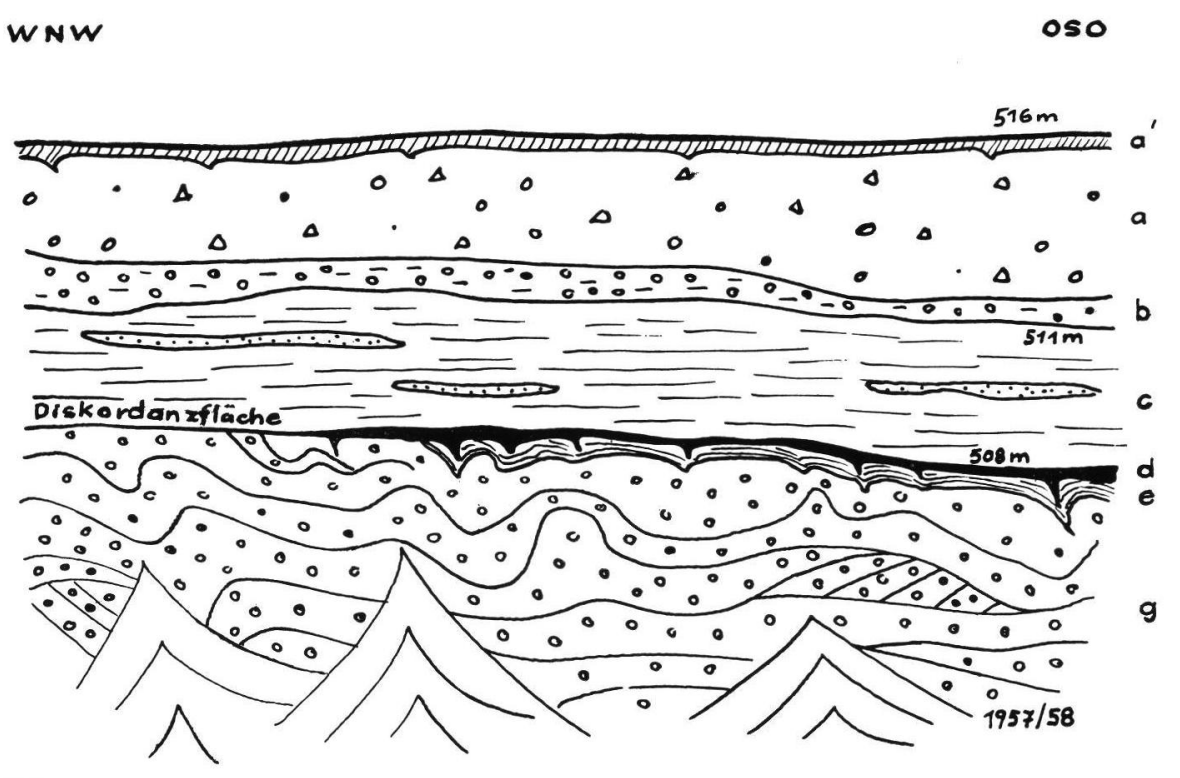

Abb. 3. Der Schichtenaufbau im rechten (südöstlichen) Drittel der Abbauwand, 1957/58.

$\left(\mathrm{a}^{\prime}=\right.$ rezenter Boden, $\mathrm{a}=$ würmeiszeitliche Grundmoräne, $\mathrm{b}=$ Moränenschotter, $\mathrm{c}=$ Seeton, $\mathrm{d}=$ Torfbank, $\mathrm{e}=$ Seekreide, $\mathrm{g}=$ Liegendschotter).

$\mathrm{a}^{\prime}$ ) rezenter Bode $\mathrm{n}$ und braune oder rotbraune Verwitterungsrinde, $5 \mathrm{~cm}$ bis (in Zapfen oder Taschen) $40 \mathrm{~cm}$.

a) Grundmorän endecke, 3 bis $5 \mathrm{~m}$ mächtig, teils grauer oder gelblicher gerölldurchsetzter kalkreicher Geschiebemergel mit einzelnen kleineren Blöcken, teils kiesiger Sand oder sandiger Kies, lose bis wandsteif.

b) Morä n e n c hot te r, $1 / 2$ bis $1 \mathrm{~m}$ mächtig, mäßig horizontal geschichtet und leidlich sortiert, tonig oder mergelig durchsetzt, lose bis wandsteif.

c) teils feinsandige Mergel, z. gr. T. aber tonige oder schluffige Feinsande, bis $3 \mathrm{~m}$ mächtig, grau-gelblich bis grau-grünlich ${ }^{13}$ ), hin und wieder Feinschichtung erkennbar, fossilfrei; im folgenden als "S e e t o n“ bezeichnet (Oberkante in etwa 511/12 m).

d) bräunlicher bis schwärzlicher torfiger Tonmergel oder schwarzer Torf, mit lignitischen Substanzen, durchwegs 2 bis $20 \mathrm{~cm}$ mächtig, darüber hinaus mit einem halben Dutzend bis $1 / 2 \mathrm{~m}$ langen, schmalen Zapfen in das Liegende eindringend ${ }^{14}$ ), typische Frostkeilformen, - aber auch die oberen horizontal gelagerten Teile in vielfältiger Weise kryoturbat gestört; im folgenden als "T o r f b a n k" bezeichnet; nur im rechten Aufschluß-Drittel (in etwa 508/09 m MH) vorhanden, keilt nach dem mittleren hin aus, und zwar vor dem hangenden "Seeton“.

e) toniger und feinsandiger Mergel, bis $1 \mathrm{~m}$ mächtig, in oberer Hälfte gelblich bis schwach bräunlich, in unterer mehr gelblich bis weißlich, sehr almsand- bis bleichsandartige

13) Die von Ebers (1960, S. 68) erwähnten braunen „L a s s e n“ sah ich nur im mittleren Aufschlußteil (2 c).

14) 1959 von Eвers (1960, S. 68) ohne diese Zapfenkeile nur als Torfbändchen beobachtet. 
Ausbildung, konchylienreich; im folgenden als "Seekreide“ bezeichnet; nur im rechten Aufschlußdrittel vorhanden, keilt nach dem mittleren hin aus, und zwar schon vor der hangenden "Torfbank“.

g) grauer und graublauer oder graugelblicher $\mathrm{L}$ i e ge nd s chot te ${ }^{15}$ ), in sich lose, im ganzen aber zu senkrechter Wandbildung fähig, 9 bis $11 \mathrm{~m}$ mächtiger sandiger Kies, vielfach mit stark mergeligem Zwischenmittel, zahlreiche Sandbänder, Gerölle kalkund zentralalpiner Herkunft, bis faust- und doppelfaustgroß, Lagerung selten horizontal, neben Delta- und Kreuzschichtung partieweise stärkeres Einfallen (bis $40^{\circ}$ NO), auffallende Stauchungs- sowie Kryoturbationserscheinungen, die besonders an den feinen schwärzlichen Bändern der Eisenausscheidungen zu erkennen sind ${ }^{16}$ ).

\section{Der Schichtenaufbau im mittleren Drittel der Abbauwand (Abb. 4)}

Dieser Teil ${ }^{17}$ ) verlief seinerzeit - etwas nach $\mathrm{N}$ ausgebogen - von $\mathrm{O}$ nach $\mathrm{W}, \mathrm{zu}$ letzt von $\mathrm{S}$ nach $\mathrm{N}$.

Höhe: bis über $20 \mathrm{~m}$, Grubensohle: etwa $497 \mathrm{~m}$, Gruben-Oberkante: etwa $517 \mathrm{~m}$.

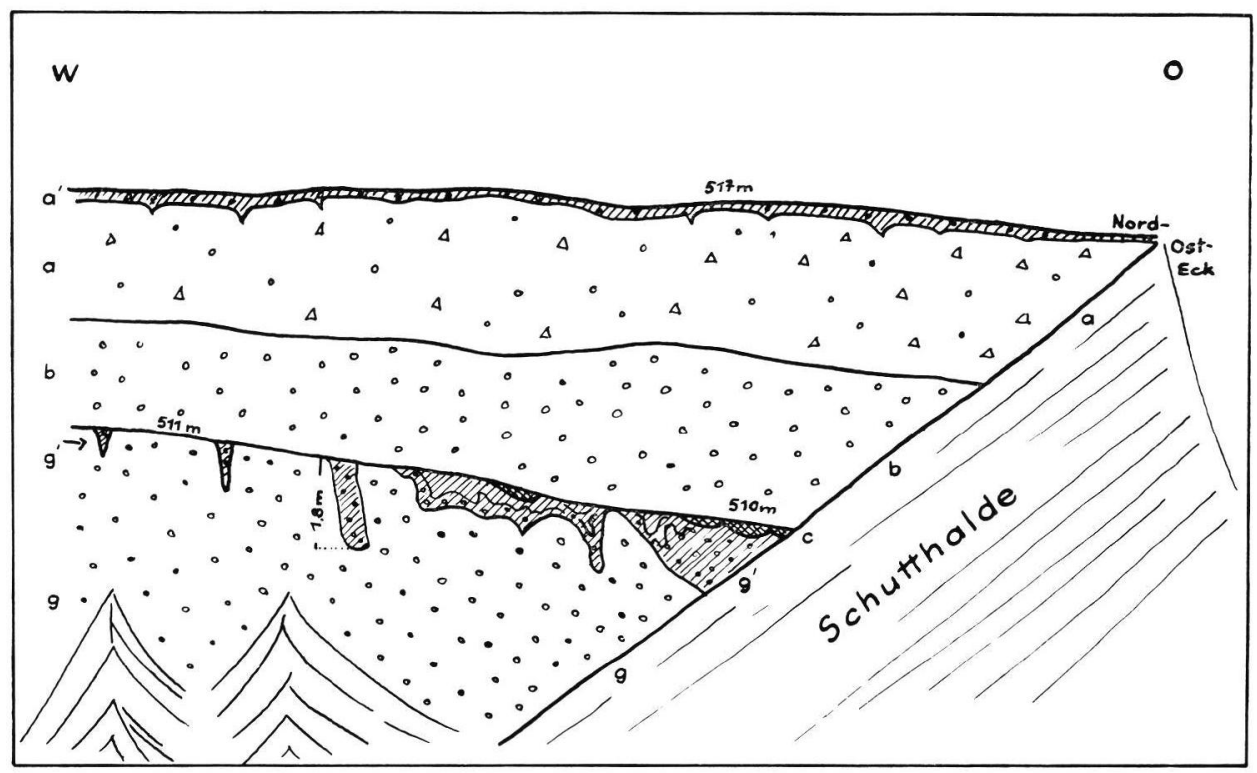

Abb. 4. Der Schichtenaufbau im Nordosteck der heutigen Kiesgrube, 1967/68.

$\left(a^{\prime}=\right.$ rezenter Boden, $a=$ würmeiszeitliche Grundmoräne, $b=$ Moränenschotter, $c=$ Seeton, $\mathrm{g}^{\prime}=$ fossiler „kaffeebrauner" Boden, $\mathrm{g}=$ Liegendschotter).

$\left.\mathrm{a}^{\prime}\right)$ rezenter Boden und braune oder rotbraune Verwitterungsrinde, wie bei 1).

a) Grundmorän end e cke, wie bei 1), jedoch nur 2 bis $3 \mathrm{~m}$ mächtig.

15) Bei Ebers (1960, S. 67) „Basalschotter".

16) Bei Ebers (1960, S. 69) „starke Pressung und stellenweise sogar Stauchung des Basalschotters" bzw. (1963, S. 88/89) "gelegentliche Andeutungen von Delta-Schüttungen oder auch eistektonische Störungen".

17) Bei Ebers (1960, S. 67) der etwa 100 m lange „Nordabschnitt des Längsprofiles“; in ihrer Abb. 2 das linke und mittlere Drittel. 
b) S chottermorän e, 1 bis 3 m mächtig, ungeschichtet und unsortiert, von groben, fast koffergroßen Blöcken - meist Molasse- oder Flysch-Sandsteine - durchsetzt, lose bis wandsteif, Geröllzusammensetzung $58: 42^{18}$ ).

c) S e e t o n, wie bei 1), hier jedoch bis $4 \mathrm{~m}$ mächtig und durch eingeschaltete Sand/Kieslagen zwei- und dreigeteilt, in den oberen Partien bräunlich, zuoberst sogar rötlichbraun, keilt nach Westen hin aus ${ }^{19}$ ).

Torfbank und Seekreide fehlen hier; dafür findet sich — vom Seeton (c) noch randlich überlagert -

$\mathrm{g}^{\prime}$ ) ein fossiler Boden, dunkelbraun, tiefgründig verwittert, entkalkt und verlehmt, durchgehend 1 bis $1^{1 / 2} \mathrm{~m}$ und $2 \mathrm{~m}$, in einer Reihe von Taschen, Trichtern, Zapfen und Schloten sogar über $2 \mathrm{~m}$ mächtig, teils in ungestörtem, unmittelbarem (Verwitterungs-)Zusammenhang mit dem liegenden Schotter, teils kryoturbat gestört (Froststrukturen, Lageveränderungen, Eiskeilfüllungen u. a. m.); im folgenden als „k affeebraune Verwitterung “ bezeichnet; Geröllzusammensetzung $\left.66: 32^{20}\right)$; Höhenlage ihrer Oberkante: etwa 510 bis $511 \mathrm{~m}$.

g) Li egend-S chotte r ${ }^{21}$ ), wie bei 1 ), jedoch mit stärkerem Sandgehalt, es treten sogar ganze Sandbänke auf; Geröllzusammensetzung $66: 34{ }^{22}$ ).

\section{Der Schichtenaufbau im linken (südwestlichen) Drittel der Abbauwand (Abb. 5).}

Während im östlichen und mittleren Aufschlußdrittel der gegenseitige Zusammenhang der einzelnen Schichten - zwar öfters durch allweilige Verschüttung unterbrochen immer wieder erkenntlich wurde, blieb dieser Teil ${ }^{23}$ ) stets für sich isoliert - vom rezenten Boden $\left(a^{\prime}\right)$ und der letzteiszeitlichen Grundmoränendecke (a) abgesehen. Es handelt sich hier um eine neue, eigene Schichtenfolge.

Höhe: bis $20 \mathrm{~m}$, Grubensohle: etwa $496 \mathrm{~m}$, Gruben-Oberkante: etwa $516 \mathrm{~m}$.

$\left.\mathrm{a}^{\prime}\right) \mathrm{rezenter} \mathrm{Boden}$ und braune oder rotbraune Verwitterungsrinde, $5 \mathrm{~cm}$ bis (in Zapfen) $40 \mathrm{~cm}$.

a) Grundmoränendecke, gelblich-grauer Geschiebemergel, etwa $1^{1 / 2} \mathrm{~m}$ mächtig.

$\left.f^{\prime}\right)$ fossiler Verwitterungshorizont, $10-30 \mathrm{~cm}$, rostrotbraun, etwa auf $3 \mathrm{~m}$ Länge sichtbar, zu f) gehörig, von a) scharf abgeschnitten ${ }^{24}$ ).

f) sandig und mergelig durchsetzter Kies, blaugrau bis gelblich-grau, lose bis wandsteif, etwa $2^{1 / 2} \mathrm{~m}$ mächtig, M o r ä n e n s ch o t t e r (partieweise auch Schottermoräne).

18) Es wurden insgesamt an 11 Stellen Geröllzählungen durchgeführt, bei jeder mit der Füllung eines 10-Liter-Eimers (jeweils 100-200 Gerölle) unter Verwendung eines $16 \mathrm{~mm}, 20 \mathrm{~mm}$ und $25 \mathrm{~mm}$-Siebes. Hier sind die Zählungen mit dem $20 \mathrm{~mm}$-Sieb - unter Umrechnung auf Prozent - wiedergegeben. Bestimmt wurden die Gerölle nach drei Gruppen: Kalkalpine (einschließlich Flysch und Molasse), Kristalline, Quarze. Im Text wurden - des leichteren Vergleiches wegen - letztere beiden zusammengefaßt. $\mathrm{Zu}$ beachten ist, daß die Geröllzählungen aus den Verwitterungsrinden zu anderen Ergebnissen führen als die aus den liegenden unverwitterten Schottern. Es wurde selbstverständlich nur Gleichwertiges miteinander verglichen.

19) Hier im W ist bei Ebers (1960, S. 68) der Seeton fast lößartig (siehe auch Text bei Anmerkung 39 ).

20) Siehe Anmerkung 18). Hier kommen aber nicht nur e in zeln e Kristallingerölle vor, wie EBERS $(1960$, S. 67) meint, sondern $17 \%$ !

21) Bei Ebers (1960, S. 68) „Basalschotter“.

22) Siehe Anmerkung 18).

23) Bei Ebers (1960, S. 69/70 u. Abb. 4) das etwa $130 \mathrm{~m}$ lange in O-W-Richtung verlaufende Querprofil.

24) War nur 1957/58 zu sehen, entzog sich damals aber - infolge seiner Lage in $16 \mathrm{~m}$ Höhe und an einer ständig nachbrechenden, senkrechten Abbauwand - der unmittelbaren Beobachtung und Untersuchung. 


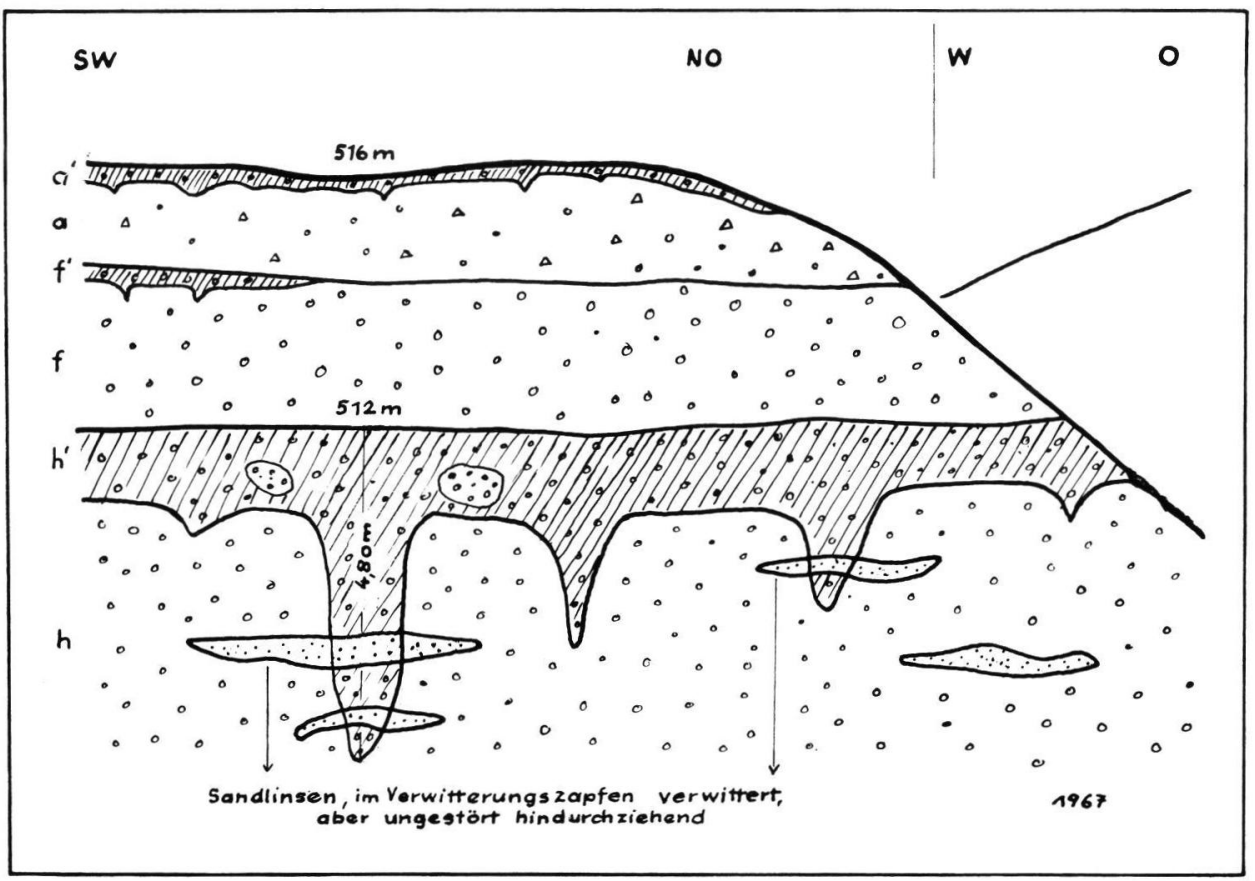

Abb. 5. Die Verwitterungsrinden im linken (südwestlichen) Drittel der Kiesgrube, 1967.

$\left(\mathrm{a}^{\prime}=\right.$ rezenter Boden, $\mathrm{a}=$ w $\ddot{\mathrm{r}} \mathrm{rmeiszeitliche}$ Grundmoräne, $\mathrm{f}^{\prime}=$ fossiler „rostrotbrauner“ Boden, $\mathrm{f}=$ Moränenschotter, $\mathrm{h}^{\prime}=$ fossiler „orangefarbener" Boden, $\mathrm{h}=$ Moränenschotter).

$h^{\prime}$ ) fossile r B oden, rostbraun bis gelblich-rötlich, durchgehend 0,8 bis 1,2 m mächtig, nach oben scharf abgeschnitten, nach unten bis $3^{1 / 2} \mathrm{~m}$ lange Zapfen (der längste mißt von der Oberkante der Verwitterung bis zur Zapfenspitze 4,8 $\mathrm{m}$ !); im folgenden als „or angef a rbene Verwitterung “ bezeichnet ${ }^{25}$ ); Geröllzusammensetzung: $53: 46^{26}$ ), Höhenlage ihrer Oberkante: $512 \mathrm{~m}$.

h) gelblicher oder gelblich-grauer $\mathrm{M}$ or änen s chot te ${ }^{27}$ ), etwa 14 m mächtig, mangelhaft sortiert und geschichtet, oben - wie an Sandbändern zu erkennen - mehr horizontal, unten - wo stärkere Sandbänke - mit z. T. kräftig einfallenden Lagen; bis kinderkopfgroße und fußlange Gerölle und Geschiebe; längere rostfarbene oder schwärzliche "Manganfahnen " — Eisenausscheidungszonen vor allem in $\pm 506 / 09 \mathrm{~m}-$ zeigen ehemalige Grundwasserstände $a^{28}$ ); der Schotter ist nur partieweise lose, im ganzen verbacken, so daß er eine senkrechte Abbauwand bildet, zahlreiche Lagen sind sogar gut verfestigt; auffallend ist - besonders in der oberen Hälfte - eine größere Zahl von angewitterten, angeätzten und auch schon richtig zersetzten Geröllen ${ }^{29}$ );

25) Nach ihrer „stark ins Gelbrot spielenden Farbe“ bezeichnet EbERs (1960, S. 70 u. a.. O.) sie als „kreßfarbene Verwitterungszone“ (siehe meine Anm. 8).

26) Siehe Anmerkung 18).

27) Bei Ebers (1960, S. 69) „Basalschotter“; so auch in den übrigen Teilen der Kiesgrube.

28) Ebenso bei BrunNacker (1962, Abb. 1, S. 126) vermerkt.

29) So auch bei BrunNaCKer (1962, S. 126), der in seiner Abbildung „morschen Schotter“ angibt. Der Einwand von Ebers (1963, S. 89), daß dies nicht zutreffe, er - im Gegenteil - sogar als „Betonschotter" verwendet würde, gilt nicht für die obere Aufschlußhälfte mit den angewitterten und z. T. richtig zersetzten Geröllen. Kies für Betonzwecke wird vornehmlich in der unteren Aufschlußhälfte gewonnen. 
dazu tritt nicht nur sandig-mergeliges, sondern auch sandig-lehmiges Zwischenmittel; umgekehrt finden sich in dem Verwitterungshorizont einige Nester von geringerer oder fehlender Verwitterung; in der unteren Schotterhälfte sind die Gerölle frisch, schlagfest und sandig-mergelig durchmischt; Geröllzusammensetzung hier $57: 42$, im ganzen Schotter $62: 37^{30}$ ).

\section{Auswertung und Deutung}

In der Hörmatinger Kiesgrube werden zwei verschiedene, miteinander nicht zusammenhängende Schichtkomplexe aufgeschlossen. Gemeinsam ist beiden lediglich die hangende, durch den letzteiszeitlichen Gletscher abgelagerte Grundmoränendecke.

Als der Gletscher dabei die Drumlins schuf, geschah das auf verschieden altem Untergrund: die Oberflächenform, die schöne Drumlinlandschaft, ist aus e in e m Guß, - um Hörmating würmeiszeitlichen Alters; ihr innerer Bau zeigt aber verschieden alte Ablagerungen, die bei jedem neuen Gletschervorstoß neuerlich „drumlinisiert“ wurden. Der ältere Schichtenkomplex liegt im westlichen Teil der Kiesgrube, der jüngere im östlichen. Hier hat u. a. der Liegend- (oder „Basal“-)Schotter ein Geröllverhältnis (kalkalpine u. ä. zu kristallinen, Quarzen u. ä.) von 66:34, stellenweise sogar 68:31, im westlichen Aufschlußteil ist das entsprechende Verhältnis bloß $62: 37$ bzw. $57: 42$ oder stellenweise sogar $50: 48$. Es handelt sich also um zwei verschiedene Schotter.

1. Der Schichtenaufbau im Aufschluß-Ostteil (Abb. 3) wäre wie folgt zu deuten:

a') post-würmeiszeitliche Verwitterungsrinde;

a) würmeiszeitliche Grundmoräne;

b) dazugehöriger würmeiszeitlicher „Vorstoß“-Schotter;

c) Seeton = würmeiszeitliche Seeablagerung am Rande des Gletschers, entstanden bei seinem Vorrücken zum Maximalstand oder während einer Gletscher-Oszillation;

$\mathrm{D}$ i s k o r d a n z, angezeigt durch Eisstauchungen und Kryoturbations-Erscheinungen im Liegenden, während das Hangende davon frei ist.

d) Torfbank = Bildung des ausgehenden letzten Interglazials oder des angehenden Würmglazials ${ }^{31}$ );

e) Seekreide $=$ Ablagerung des ausgehenden letzten Interglazials oder des angehenden Würmglazials ${ }^{31}$ ); nach Verlandung des Sees bildete sich hier ein Moor (mit der Ablagerung von d);

g) Schotter einer mittelpleistozänen Eiszeit.

2. Der Schichtenaufbau im Aufschluß-Mittelteil (Abb. 4) wäre wie folgt zu deuten:
$\left.a^{\prime}\right)$
a)
b)
c) wie bei 1);
D i s k o r d a n z, wie im Aufschluß-Ostteil;
$\mathrm{g}^{\prime}$ ) mächtige fossile („kaffeebraune“) Verwitterungsrinde einer mittelpleistozänen Interglazialzeit;
g) Schotter einer mittelpleistozänen Glazialzeit.

30) Siehe Anmerkung 18).

31) Siehe dazu die folgenden Ausführungen (Text bei Anm. ${ }^{42-45}$ ). 
3. Der Schichtenaufbau im Aufschluß-Westteil (Abb. 5) wäre wie folgt zu deuten:
a) $\}$ wie bei 1) und 2);
$f^{\prime}$ ) riß/würm-interglaziale Verwitterungsrinde ${ }^{32}$ );
f) riß-eiszeitlicher Moränenschotter;
$h^{\prime}$ ) mächtige fossile („orange-farbene“) Verwitterungsrinde einer mittelpleistozänen Interglazialzeit;
h) moränennaher Schotter einer mittelpleistozänen Glazialzeit.

\section{Begründung und Auseinandersetzung}

$\mathrm{Zu} \mathrm{a)} \mathrm{und} \mathrm{b):}$

Grundmoränendecke und li egender Schotter (bzw. moränennaher Schotter) werden durch keine Diskordanz getrennt ${ }^{33}$ ). Beide gehören zusammen; letzterer ist als "Vorstoßschotter" die fluvioglaziale Entsprechung zu der unmittelbar danach abgelagerten glazialen Grundmoränendecke.

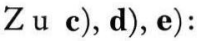

Seeton, Torf und Seekreide gehören keineswegs einer in sich geschlossenen Serie von "Seesedimenten" an ${ }^{34}$ ). Der Seeton ist von dem Torf durch eine deutliche Diskordanz getrennt. Die liegenden Schichten sind durchgehend glazialgestaucht und frostgestört, die hangenden sind davon frei.

Seekreide und Torf sind zudem nicht eiszeitliche Bildungen, sondern solche eines Interglazials (oder ausgehenden Interglazials oder auch warme Zeitabschnitte innerhalb eines beginnenden Glazials). Der hangende Seeton jedoch kam während eines folgenden echt glazialen Zeitabschnittes zur Ablagerung.

Der S e e to n besitzt keine warmzeitliche Verwitterungsrinde ${ }^{35}$ ). Seine bräunliche Verfärbung in den oberen und sogar rötlichbraune in den obersten Lagen ${ }^{36}$ ) ist durch solifluidale Einschwemmung vom Ufer her entstanden ${ }^{37}$ ). Ebenso spricht seine Fossilleere ${ }^{38}$ ) für glazialzeitliche Entstehung. Das zeigt auch seine mikromorphologische Untersuchung - mit dem Ergebnis von überwiegend „löß-typischen“ Kornfraktionen, wonach eine äolische Komponente zu vermuten wäre (Schwemmlöß-Erscheinungen) ${ }^{39}$ ).

32) Diese Deutung ist wahrscheinlich, aber nicht zwingend. Gründe: siehe Anmerkung ${ }^{24}$ ). Möglich wäre auch eine Würm-interstadiale "Anwitterung" (statt einer R/W-interglazialen Verwitterung). Siehe auch die Ausführungen im folgenden Kapitel ( $\mathrm{zu} \mathrm{f}^{\prime}$ ).

33) Eine solche nimmt EBERs (1960, S. 67) an.

34) So bei Ebers (1960, S. 68/69): „lakustres Profil“, „Seesedimente ca. 41/2 m mächtig“, „Seenprofil“ - mit Seekreide, Torfbändchen und Seeton.

35) Ebers (1960, S. 68/69) schreibt von verwittertem Seeton und langanhaltender Verwitterung an der Oberkante der Seesedimente.

36) Darauf beziehen sich gewiß die braunen „Lassen“ von EbERs (1960, S. 68), von denen sie anscheinend die Seeton-Verwitterung herleitet.

37) Vom Ufer, d. h. nach aller Wahrscheinlichkeit von der Landoberfläche mit der kaffeebraunen Verwitterungsrinde.

38) Wenn Gross meint (siehe Ebers 1960, S. 72) daß „Pollen ... mit einiger Wahrscheinlichkeit auch im hangenden Seeton zu erwarten" wären, „durch Verwitterungscinflüsse ... zerstört worden seien", so ist das eine bloße Annahme. Auch dort, wo der Seeton ganz frisch (in grau-gelblich-bläulich-grünlicher Färbung) entgegentritt, von Verwitterung keine Rede sein kann, ist er völlig fosilleer.

39) Siehe Eвers (1960, S. 73); bestimmt durch E. SснӧNHALs, Bundesanstalt für Bodenforschung, Hannover. 
Der zusammengehörige hangende Komplex besteht also aus c) - b) - a). Seeton $=$ limnoglaziale Ablagerung; eisrandnaher "Vorstoßschotter" = fluvioglaziale Ablagerung; Grundmoräne = glaziale Ablagerung.

Dem würmeiszeitlichen Hauptvorstoß (W II) entspricht ohne Zweifel die Grundmoränendecke nebst dem zugehörigen „Vorstoßschotter“ (a und b). Zu erwägen wäre lediglich, ob der Seeton (c) zu W I zu stellen wäre. Das ließe sich exakt genug weder beweisen noch widerlegen. Auffallend ist, daß die Froststörungen und Eisstauchungen nur das Liegende (nach oben hin bis zur Torfbank) ergriffen haben. Man ist daher geneigt, die hangenden (limnoglazialen, fluvioglazialen und glazialen) Schichten $(c, b, a)$ - wie hier geschehen - zu einem Komplex zusammenzufassen. Es sei aber durchaus die andere Möglichkeit offen gelassen, daß der limnoglaziale Seeton abzutrennen und in W I zu stellen wäre.

Der zusammengehörige liegende Komplex besteht aus d) und e): Seekreide und Torfbank. Sie sind von dem hangenden Komplex deutlich abgesetzt; neben den beiden fossilen Böden bilden sie die wichtigsten Teile des Hörmatinger Aufschlusses.

Das Pollenspektrum der Torf ba nk - mit Überwiegen von Picea (zuletzt 44\%) und Pinus (zuletzt 40\%), daneben Alnus $(6 \%)$ und Betula $(3 \%)$ - spiegelt eine FichtenKiefernzeit wieder $\left.{ }^{40}\right)$. Der Vergleich mit Pollenspektren des westlich benachbarten Alpenvorlandes ${ }^{41}$ ) würde für eine Altersgleichheit mit den R/W-interglazialen Schieferkohlen sprechen, in denen ebenso Picea und Pinus weitaus vorherrschen. Wie hier handelt es sich um eine Bildung des ausgehenden R/W-Interglazials, nicht eines Würm-Interstadials ${ }^{42}$ ).

An dieser Stelle erscheint es notwendig, in Erinnerung zu bringen, was PENCK unter einem Interstadial verstand: die Zeit einer großen Gletscherschwankung, jedoch ohne Wiederbewaldung und ohne die damit zusammenhängende Bodenbildung (siehe auch Schaefer, 1953, S. 7). Alle pedologischen und biologischen Merkmale jedoch, die Bodenbildung infolge Wiederbewaldung (und eustatische Meeresspiegelschwankungen) zur Voraussetzung oder zur Folge haben, zwingen von vornherein zur Annahme einer Interglazialzeit. Das Fehlen eines interstadialen Waldes im Alpenvorland vertritt auch REICH (1953, S. 439).

Waldbedeckung und damit zusammenhängende Bildung des braunen Waldbodens dürften nach wie vor das sicherste allgemeine Kennzeichen einer Interglazialzeit bleiben, auch wenn Gross (1958, S. 156) diese meine Definition als "das größte Hindernis“ zur Lösung des Problems der Würm-Gliederung bezeichnet. Worin das "größte Hindernis" bestehen soll, ist nicht recht verständlich, wenn man die Gross'sche Definition mit meiner vergleicht. Bei ihm: Interglazial = Zeit mit genügend langdauerndem warmen Klima, das Eis in den Alpen bis mindestens auf den heutigen Umfang abgeschmolzen; Interstadial = Zeit mit subarktischem bis kühl-temperiertem Klima, das Eis noch nicht auf dem heutigen Umfang zurückgeschmolzen. Bei mir: Interglazial = Zeit eines großen Gletscherrückzuges mit Wiederbewaldung des Alpenvorlandes und damit zusammenhängender Bodenbildung; Interstadial = Zeit einer größeren Gletscherschwankung ohne Wiederbewaldung und ohne damit zusammenhängende Bodenbildung.

Im übrigen: Was heißt bei Gross (1958) genügend langdauernd und warm? Was heißt Eisrückzug noch nicht bis zum heutigen Umfang? Wo liegen die Grenzen? - Da scheint mir die Bodenbildung nach wie vor ein besseres und vor allem viel weiter verbreitetes Hilfsmittel, ein Interglazial von einem Interstadial zu trennen - zumindest im Umkreis der Alpen.

40) Leider waren nur die unteren Teile des Torfes erfaßbar, (EвEns, 1960, S. 72). Nach der Zunahme von Alnus $(2-3-6 \%)$ und Picea $(27-43-44 \%)$ - bei gleichzeitiger Abnahme von Pinus $(51-48-40 \%)$ könnte man für die oberen Teile des Torfes eine weitere Wärmezunahme erwarten.

Unglücklicherweise sind meine eigenen Torf- sowie Seekreide- und Seetonproben seit einem Umbau meines Hauses noch nicht wieder zum Vorschein gekommen.

41) Siehe Reich (1953) zu den Interglazialbildungen von Großweil und Pfefferbichl.

42) Durch Gross wurde EBErs (1960, S. 73) auf die Ahnlichkeit des Hörmatinger Torfdiagramms mit den Pollenzonen 11 und 13 von Großweil hingewiesen. Diese spiegeln aber zwei wärmere Zeitabschnitte des ausgehenden R/W-Interglazials wider, nicht eine Interstadialzeit zwischen zwei Würmhochständen. (Reich 1953, S. 431, 439/40). Ebers, Kraus und Gross verlegen das Hörmatinger Torfprofil dennoch in die Würmeiszeit. 
Die geochronologische Radiokarbon ${ }^{14} \mathrm{C}$-Datierung ${ }^{43}$ ) der Torfschicht ergab ein Alter von $45300 \pm 1000 \mathrm{~J}$.v.h. (für Torf) und älter als $53000 \mathrm{~J}$.v.h. (für Holz) ${ }^{44}$ ). Die Bildungszeit fällt also in jedem Falle vor den Hauptvorstoß der letzten Vergletscherung.

Ablauffolge also: Torf von Hörmating $45300 \mathrm{~J} . \mathrm{v} . \mathrm{h}$. - kleinerer, kürzerer erster Gletschervorstoß (W I) etwa zwischen 43000 und $35000 \mathrm{~J}$. v. h. - Tannenzapfen von Steingaden 45) $33 / 34000 \mathrm{~J}$. v. h. - Hauptgletschervorstoß etwa zwischen 25000 und $15000 \mathrm{~J}$. v. h.

Ob dementsprechend zum kleineren W I-Gletschervorstoß nur die "sehr kalten“ Zeitabschnitte zwischen etwa 45000 und $35000 \mathrm{~J}$. v. h. der von Woldstedt (1962, S. 121, Abb. 1) entworfenen letzteiszeitlichen Klimakurve gehören oder auch noch die „kalten“ Zeitabschnitte zurück bis 70000 J.v.h., möchte man im Alpenraum eher im ersten Sinne entscheiden. Denn die Gletscher sind in der Würmeiszeit bestenfalls zweimal ins Alpenvorland getreten; das wäre dann während der "sehr kalten“ Zeitabschnitte 25/15000 (W II) und 43000/35000 J.v. h. (W I) der Fall gewesen.

Insofern dürfte die Feststellung WoldsTEDTs (1962, S. 122) etwas zu modifizieren sein, wonach bereits in seinem "Altwürm“ (ca. 70000-53000 J.v.h.) mit einem ausgeprägt eiszeitlichen Klima (nahezu volleiszeitliche Klimaverhältnisse mit zwischengeschalteten interstadialen Schwankungen) zu rechnen sei. In dieser Zeit werden im Alpenvorland nur „kaltzeitliche“, noch nicht „eiszeitliche“ Verhältnisse geherrscht haben. Nach der WoLDstedTschen Klimakurve müßten Holz und Torf von Hörmating in das (beginnende) Würmglazial, nicht in das ausgehende Riß/Würm-Interglazial gestellt werden.

Für die S e e k r e i d e lautet die von DeHM ${ }^{46}$ ) nach dem Fossilinhalt getroffene Klimadiagnose: temperiert, etwas kühler als heute. Dieser Feststellung kommt selbstredend weit mehr Gewicht zu als jener Außerung, wonach die „Beimengung von etwas Feinsand und Ton" dafür spräche, daß die Pflanzendecke nicht ganz geschlossen gewesen und deswegen ein kaltes, mehr oder weniger subarktisches Klima geherrscht habe ${ }^{47}$ ). Nun: der Seekreide ist nicht nur „etwas" Feinsand und Ton beigemengt, sondern sie ist überhaupt mehr oder weniger schluffig, tonig, mergelig oder feinsandig ausgebildet. Es handelt sich in fazieller Hinsicht um den gleichen "Almsand“, der z. B. in den Mooren nördlich von München unter, in oder neben dem Torf auftritt und postglaziales, bestenfalls spätglaziales Alter besitzt $\left.{ }^{48}\right)$.

Das paßt nahtlos in die bisher entwickelte Rekonstruktion: Ablagerung der Seekreide in einem Seebecken ${ }^{49}$ ) und Verlandung mit Vermoorung und Torfbildung ${ }^{50}$ ). Danach im

43) Durch H. DE Vries erfolgt; siehe Ebers 1960, S. 71. Je doch wurde die Torfschicht datiert, nicht die kaffeebraune Verwitterungsrinde, wie Ebers (1960, Zusammenfassung S. 64) schreibt.

44) Es erübrigt sich, auf die Diskussion zwischen Brunnacker (1962) und Ebers (1963) über die verschiedene Alterswertigkeit von Torf und Holz einzugehen.

$\mathrm{Ob}$ es sich nun um „eingeschwemmte Holzreste“ (EBERs, 1960, S. 71) oder um „ein Nest von einigen Holzstückchen“" oder „einen vereinzelten Holzrest“ (EbERs 1963, S. 89) handelt, - dennoch sollte man EBERs folgen und der Torfdatierung das größere Gewicht geben. Es steht aber auch die Holzdatierung in keinem Widerspruch zu den anderen Geländebefunden und meinen Deutungen.

45) Drei Radiokarbon-Datierungen 1967 u. 1968 durch das Hahn-Meitner-Institut f. Atomphysik in Berlin-Wannsee. Tannenzapfen von cand. geol. H. Ch. HöfLE (FU Berlin) 1967 gefunden, bildet ein Ergebnis seiner Diplomarbeit (Kartierung von Blatt Bayersoien). Siehe HöFle (1969).

46) Siehe Ebers (1960, S. 73).

47) So Gross (siehe Ebers 1960, S. 73).

48) Für das Blatt 7736, Ismaning, des geolog. Kartenwerkes 1:25000 von Bayern (1964) hat M. Brunnacker (S. 76) aus einem Kalklager (an der Brennermühle) 19 Molluskenarten festgestellt; dabei treten - bis auf eine - auch die von Hörmating auf, vor allem die hier sehr zahlreiche Valvata piscinalis alpestris.

49) Dabei dürfte es sich nur um eine lokale Seebildung, nicht „um einen Vorläufer des Rosenheimer Sees" gehandelt haben, wie Ebers (1963, S. 89) vermutet. Ein solcher wird kaum mehr als bestenfalls $480 \mathrm{~m} \mathrm{MH}$ gehabt haben, - die Hörmatinger "Seesedimente" liegen aber bei etwa $510 \mathrm{MH}$.

50) Die Verlandung erfolgte zu diese r Zeit, also nach Ablagerung der Seekreide, bei der Vermoorung und Torfbildung, - nicht, wie EBErs (1960, S. 69) meint, erst nach Ablagerung des Seetones. 
Verlaufe eines würmeiszeitlichen Gletschervorstoßes Glazialstauchung und Froststörung (= Diskordanz zwischen Torf und Seeton).

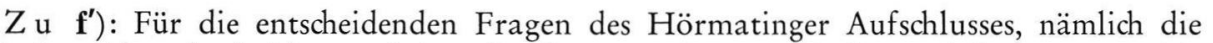
nach dem Alter der beiden mächtigen fossilen Verwitterungsrinden und ihrem gegenseitigen Verhältnis, ist nicht von ausschlaggebender Bedeutung, ob es sich bei dem unter der Grundmoräne des letzten Gletschervorstoßes liegenden Verwitterungshorizont um eine tiefgründige Verwitterung des Riß/Würm-Interglazials (mit echter Bodenbildung) handelt oder nur um eine flachgründige ("Anwitterung“) des W I/ W IIInterstadials. Nach der Ausbildung der zugehörigen Schicht (Moränenschotter bis Schottermoräne) würde man diese aber der Rißeiszeit zuordnen und die Verwitterung auf ihr dem Riß/Würm-Interglazial.

$\mathrm{Zu} \mathrm{g}$ ): Ob der 9 bis $11 \mathrm{~m}$ mächtige $\mathrm{L}$ i e ge n d-Schotter noch jungdiluvialen Alters ist, erscheint kaum denkbar: Der hangende Torf (mit $45300 \pm 1000$ ) und sein Holz (mit älter als 53000 J.v. h.) sind älter als der letzte bis weit hinaus ins Alpenvorland reichende jüngere würmeiszeitliche Gletschervorstoß (W II). Der ältere würmeiszeitliche Gletschervorstoß (W I) hatte aber bei seiner geringeren Entfaltung und Zeitdauer nicht die Möglichkeit zu solch mächtigen Schotter-Ausstrahlungen. Nach der z. T. stark grobkörnigen Ausbildung des Liegend-Schotters kann aber die zugehörige Gletscherstirn nicht sehr weit entfernt gelegen haben. Schließlich zeigt die kaffeebraune Verwitterungsrinde, die sich auf dem Liegend-Schotter gebildet hat, daß dieser schon aus dem Mittelpleistozän stammt. Wenn unmittelbar über der mächtigen kaffeebraunen Verwitterungsrinde eine R/W-Interglazialbildung fehlt, so spricht das in keiner Weise dagegen. Ex nihilo nihil! Interglaziale Bildungen sind in den Alpen (infolge der Glazialerosion) und im Alpenvorland (infolge frühglazialer Erosion und solifluidaler Denudation) so selten, daß man aus ihrem Fehlen keine Schlüsse ziehen kann ${ }^{51}$ ).

$\mathrm{Zu} \mathbf{g}^{\prime}$ ): Die Auffassung, daß die kaffeebraune Verwitterungsrinde zur orangefarbenen gehöre, beide die Bodenbildung einer einzigen Landoberfläche wären, jene den ursprünglichen Boden am Oberhang und diese den durch Solifluktion verstärkten Boden am Hangfuß darstelle ${ }^{52}$ ), trifft nicht $\mathrm{zu}$.

Von einer Hanglage ist nichts zu erkennen. Die Oberkante des kaffeebraunen Bodens liegt bei $510 / 11 \mathrm{~m}$, die des orangefarbenen Bodens bei $512 \mathrm{~m}$; die Entfernung dazwischen beträgt $120 \mathrm{~m}$, Neigung des (angenommenen) Hanges: noch unter 1/2 Grad ${ }^{53}$ )! An Solifluktionsbewegungen ist also kaum zu denken. Von einem Abfließen des orangefarbenen Bodens ${ }^{54}$ ) „hinab“ zum kaffeebraunen ${ }^{55}$ ) ist auch nichts zu sehen. Daß hier ein Rücken vom Gletscher geköpft und sein Boden von der Glazialerosion aufgearbeitet worden sein soll, scheidet ebenso aus. Die Verwitterungsmächtigkeit des orangefarbenen Bodens geht bis 1,20 $\mathrm{m}$ und - in Zapfen und Trichtern - bis 4,80 m (!) tief hinab ${ }^{56}$ ), die des kaffeebraunen Bodens erreicht bis 1,5 $\mathrm{m}$ und - in Trichtern und Zapfen - bis 2,5 $\mathrm{m}$ Mächtigkeit. Von einer Aufarbeitung und Umlagerung des orangefarbenen Bodens - entgegen

51) $\mathrm{Zu}$ dieser Frage der diluvialen Erosion und Akkumulation - speziell ihrer besonders starken Wirkung in den "frühglazialen“ Zeitabschnitten - siehe meine Arbeit von 1950.

52) So bei Brunnacker, 1962.

53) Die Abbildung von Brunnacker (1962, S. 126) gibt die Höhen- und Hangverhältnisse unrichtig wieder.

54) Dieser ist bei Brunnacker (1962, S. 125) der Boden in Oberhanglage („einwandfreier BHorizont einer interglazialen Parabraunerde").

55) Dieser ist bei Brunnacker (1962, S. 125/127) der gleichalte Boden in Unterhang- und Hangfußlage plus Fließerde (vom Oberhang).

56) Diese schon von Ebers (1960, S. 70) beobachteten und erwähnten langen Verwitterungszapfen sind in der Abbildung von BrUNNACKER nicht wiedergegeben. 
der Gletscherbewegung (!) - in Richtung zum kaffeebraunen ist auch nichts zu sehen. Daß der kaffeebraune Boden stärker verlehmt ist, liegt weniger an einer Fließerde-Struktur, sondern daran, daß er in erheblichem Ausmaße kryoturbat gestört und frostverwürgt worden ist ${ }^{57}$ ).

Nicht zutreffend ist ebenso die Auffassung, daß die kaffeebraune Verwitterungsrinde und die vermeintliche Seeton-Verwitterung gleichalte Bildungen wären, beide zu derselben Landoberfläche gehörten ${ }^{58}$ ). Von der fehlenden Verwitterungsrinde des Seetons war bei dessen Behandlung schon die Rede ${ }^{59}$ ). Aber selbst wenn er eine besäße, wäre sie jünger; das wird durch die Auflagerung des Seetons auf die kaffeebraune Verwitterung und die Einbettung in sie bezeugt ${ }^{60}$ ). Mehrfach — zuletzt durch Ausgrabungen im Herbst 1967 - konnte das bestätigt werden; dabei trat der Seeton wieder frisch und unverwittert entgegen, - ganz gleich, ob auf der tiefgründig zersetzten kaffeebraunen Verwitterungsrinde lagernd oder auf zuvor erodiertem, also unverwittertem Untergrund ${ }^{61}$ ).

Kurzum: Die kaffeebraune Verwitterungsrinde ist älter als der obere würmeiszeitliche Komplex (mit Seeton - Vorstoßschotter - Grundmoränendecke).

Es bestände lediglich die Möglichkeit eines zeitlichen Zusammenhangs mit dem unteren, dem Seekreide/Torf-Komplex, etwa in folgendem Sinne: In einem (später verlandeten) Seebecken zuerst Seekreide-Ablagerung, danach Torfbildung, - zur selben Zeit auf dem umliegenden höheren Land aber interglaziale Verwitterung und Bildung des kaffeebraunen Bodens.

Etwa in dieser Weise - nur mit Einschluß des Seetones, also ihres ganzen "Seeprofiles" hatte es sich wohl auch Ebers (1960, S. 69 u. 74) vorgestellt. Dabei erachtet sie als einen „sehr wesentlichen Punkt für die Deutung des Profils“ die Tatsache, daß der Seekreide/Torf-Komplex nicht ganz bis unter (besser: a n) die kaffeebraune Verwitterungsrinde heranreicht und auch mit seiner Oberkante knapp unter deren Unterkante bleibt (S. 68 und 75). Ganz trifft das nicht zu: Seekreide/Torf liegen bei ca. $508 / 09 \mathrm{~m}$ und die kaffeebraune Verwitterungsrinde reicht von $510 / 11 \mathrm{~m}$ bis ca. $508 \mathrm{~m}$ hinab. Davon abgesehen - es liegt doch jedes Seebecken tiefer als seine Umgebung! Wesentlicher erscheint, daß der Seekreide/Torf-Komplex nur an die kaffeebraune Verwitterungsrinde he ra n re i cht, aber keine unmittelbare Beziehung zu ihr hat.

Später läßt Ebers $(1963$, S. 87) „das Torfbändchen, vertreten durch einen $10-12 \mathrm{~cm}$ breiten Gyttja-Streifen“, unmittelbar unter die kaffeebraune Verwitterungszone reichen. Nun: Da müßte zuerst der Nachweis erbracht werden, daß dieses Gyttja-Vorkommen die tatsächliche Fortsetzung des Torfes darstellt. Leider habe ich es bei meinen Besuchen nicht gesehen.

In ihrer Schilderung der Hörmatinger Kiesgrube von 1965 lehnt sich Ebers im Text an ihre Darstellung von 1960 und 1963 an (S. 217: „Weiter nach N hin endeten diese... See- und Moorablagerungen, und einige Meter nördlicher setzte eine... bis zu $3 \mathrm{~m}$ dick werdende braune Zone von Verwitterungsmaterial und Auelehm ein"). In der zugehörigen Abbildung (S. 216) verlegt sie jedoch das "Torfbändchen" mitten in den "kaffeebraunen Boden“. Aber selbst mit Hilfe eines guten Vergrößerungsglases ist dort, wo ihr Pfeil hinweist, nur ein Schattenstrich, aber kein Torfbändchen zu erkennen. Es hat hie r a u ch n i e gelege $\mathrm{n}$ - selbst nicht nach ihren eigenen

57) Hierbei, wie aber auch bei der Altersbestimmung neigt man zum Urteil von EBERs (1963, S. 88), wonach "K. BRUNNACKER zur Konstruktion eines hypothetischen Schemas... mit starker Vereinfachung der Naturgegebenheiten" verführt worden ist.

58 So bei Ebers (1960, S. 68/69).

59) Siehe Text bei den Anmerkungen 35-39).

60) Auch Ebers (1960, S. 68) hat das beobachtet: „Die... Seetone ... senken sich ... wie ein flache Beckenfüllung in die kaffeebraune Schicht ein." Allerdings zieht sie daraus den auffallenden Schluß, daß "Seesediment" (hier = Seeton) und (kaffeebraune) "Verwitterungsrinde" dieselbe "wenn auch etwas verbogene" Oberkante hätten, daher auch dieselbe Landoberfläche bildeten. Nun: Aus der gleichen Höhenlage läßt sich noch lange kein Schluß auf das gleiche Alter ziehen. Wie an der heutigen Erdoberfläche - haben auch früher schon verschieden alte Verwitterungsrinden nebeneinander gelegen.

61)Letzteres wurde von Ebers (1960, S. 68) beobachtet. Der (Eisrand-)See hat demzufolge auf erodiertem bzw. denudiertem, aber auch auf unverändertem Untergrund sedimentiert. Daraus ist also kein Rückschluß möglich. Ebenso nicht aus einem fossilen Bacheinschnitt (EBERS 1960, S. 69), - zumindest bis dessen subglaziale Entstehung mit Sicherheit ausgeschlossen worden ist. 
drei Darstellungen: Weder nach der von 1960 (siehe vor allem ihre Abb. 2, wo das Foto von 1965 einen Ausschnitt der nördlichen Abb.-Hälfte, also links vom „Bacheinschnitt“ wiedergibt) noch nach der von 1963 (hier liegt der nach ihrer Meinung das Torfbändchen vertretende $10-12 \mathrm{~cm}$ breite Gyttjastreifen unter dem kaffeebraunen Boden) und auch nicht nach der Darstellung von 1965 (siehe den oben wiedergegebenen Text zu ihrer Abbildung).

Gegen eine Verbindung der kaffeebraunen Verwitterungsrinde mit dem Seekreide/ Torf-Komplex sprechen gewichtige paläoklimatologische und paläopedologische Gründe: Seekreide und Torf spiegeln das ausgehende letzte (R/W-)Interglazial wieder, - nach Seebewohnern und Bewaldung (Fichten/Kiefern) kühler als in der Gegenwart (und als im Höhepunkt des letzten Interglazials). Die kaffeebraune Verwitterungsrinde repräsentiert nach Verlehmungs-Intensität und -Mächtigkeit aber eine ganze Interglazialzeit.

Ihre Zuordnung in das letzte (R/W-)Interglazial ${ }^{62}$ ) ist auch nach pedologischen Gesichtspunkten unwahrscheinlich. Natürlich ist aus fehlenden oder geringmächtigen interglazialen Böden kein Rückschluß auf ein Interglazial oder dessen Länge möglich. Es ist aber umgekehrt in der Regel erlaubt, aus dem Maximalbet rag einer Verwitte r u ngsinde auf Alter und Zeitdauer zu schließen. Noch nie ist eine solche von 2 oder 3 oder gar $4 \mathrm{~m}$ Mächtigkeit in das Postglazial gelegt worden, auch nicht in das R/WInterglazial. Dazu gehören viel längere Zeiträume, die meist bis ins Altpleistozän zurückreichen.

Alle jungpleistozänen Ablagerungen haben im gesamten näheren und weiteren Umkreis von Hörmating maximale Verwitterungsmächtigkeiten von $45 \mathrm{~cm}$ (und nur in Taschen und Zapfen bis $90 \mathrm{~cm}$ ). Das gilt z. B. für die ältesten, in den obersten NT liegenden würmeiszeitlichen Fluvioglazialschotter, die seit ihrer Ablagerung ununterbrochen an der Erdoberfläche anstehen, also auch ununterbrochen der Verwitterung ausgesetzt sind. Für altwürmeiszeitliche Ablagerungen aber, die nur eine Zeit lang an der Erdoberfläche verwittern konnten, danach aber von jungwürmeiszeitlicher Grundmoräne überdeckt wurden, kann man nur einen Teil dieser Verwitterungsmächtigkeit ansetzen. Dieser Betrag schrumptt noch mehr zusammen, wenn man berücksichtigt, daß in dieser Zeit (der fossilen „Altwürm“-Bodenbildung) das Klima kühler war, vielleicht subarktisch — und lediglich Fichten-Kiefern-Wälder (oder nur Bäume?) zuließ, mithin der Bildung von Verwitterungsrinden vom Typ der braunen Waldböden äußerst ungünstig war. Mehr als $5-10 \mathrm{~cm}$ Verwitterungsmächtigkeit - und diese in wenig tiefgründiger Ausbildung, eher als „Anwitterung" - wird man für ein würmeiszeitliches Interstadial kaum erwarten können.

Unter den rißeiszeitlichen Ablagerungen liegen jene Hörmating am nächsten, die sich etwa $20 \mathrm{~km}$ nordwestlich, von Wolfersberg über Zorneding und Purfing nach Anzing erstrecken oder jene, die $20 \mathrm{~km}$ westsüdwestlich zwischen dem Mangfallknie und Holzkirchen liegen. Ihre Verwitterung reicht im allgemeinen bis $1,5 \mathrm{~m}$, in keinem Falle tiefer als $1,7 \mathrm{~m}$ hinab ${ }^{63}$ ). Das sind - wohlgemerkt - Verwitterungsrinden, die immer an der Erdoberfläche lagen und zwei Warmzeiten erlebt haben (Riß/Würm-Interglazialzeit und Postglazialzeit). Wo es aber zu einer Überdeckung durch würmeiszeitliche Grundmoräne kam, wird man diese Beträge um mindestens den Wert der würmeiszeitlichen (stärker mechanischen) und postwürmzeitlichen (stärker chemischen) Verwitterung verringern müssen; man käme dann auf 0,6 oder bestenfalls bis 1,2 m Verwitterungsmächtigkeit für das Riß/WürmInterglazial. In diesen Grenzen halten sich auch alle im Bereich des diluvialen Inn-Chiemsee- wie des Isar-Loisachgletschers entdeckten fossilen Böden des Riß-Würm-Interglazials $\left.{ }^{64}\right)$.

62) So bei BrunNacker (1963).

63) Bei größeren Beträgen handelt es sich fast immer um ältere als rißeiszeitliche Bildungen.

64) Entsprechende Beispiele werde ich in meiner bevorstehenden Arbeit über den diluvialen Isar-Loisachgletscher anführen. 
Die fossile kaffeebraune Verwitterungsrinde im mittleren Teil der Hörmatinger Kiesgrube wird aber bis über $2 \mathrm{~m}$ mächtig. Von einer „Bodenverdickung“ durch Solifluktionstransport und Fließerde-Überdeckung sollte man nicht sprechen ${ }^{65}$ ). Es sind einwandfreie Verwitterungszapfen vorhanden ${ }^{66}$ ). Die fehlende Bodenhorizontierung ${ }^{67}$ ) braucht nicht wunder zu nehmen, sie geht den meisten alten tiefgründig verwitterten Böden ab. Außerdem treten hier die erwähnten Froststörungen und Glazialstauchungen hinzu, die das ursprüngliche Gefüge, aber auch die ehemalige - gleichmäßigere - Mächtigkeit der Verwitterungsrinde verändert haben. Dabei kann sich natürlich auch Fließerde zugesellt haben. Aber noch bei den letzten Ausgrabungen (1967, am Nordende der kaffeebraunen Verwitterungsrinde) fand sich - neben gestörten und lageveränderten Partien - echter, autochthoner Kies-Verwitterungslehm von gut 1,5 $\mathrm{m}$ (und in Taschen und Zapfen bis $2 \mathrm{~m}$ ) Mächtigkeit ${ }^{68}$ ).

Bei diesen Verwitterungsbeträgen ist nur e in e Deutung möglich. Rißeiszeitliche Ablagerungen besitzen solche nicht einmal bei ununterbrochener Lage an der Erdoberfläche - ganz zu schweigen, wenn sie seit der Würmeiszeit überdeckt wurden. Ein altpleistozänes Alter scheidet aus vielerlei Gründen aus. So bleibt: Es ha ndelt sich u m die Verwitterungsrinde aus einer älteren mittelpleistozänen Eiszeit.

Die nächsten - den Hörmatinger Schotter- und Verwitterungsbildungen ähnlichen finden sich $4 \frac{1}{2} \mathrm{~km}$ nordwestlich in der großen Kiesgrube bei Biberg sowie $61 / 2 \mathrm{~km}$ nordwestlich in den Kiesgruben bei Weng, vor allem in den beiderseits der Straße nach Hohenthann. In der ersteren südöstlich von Biberg erscheinen in einer $4 \mathrm{~m}$ mächtigen Deckschicht zwei verschiedene Verwitterungsrinden: Eine obere mit 1-1 1/2 $\mathrm{m}$ (und in Trichtern und Zapfen bis $21 / 2 \mathrm{~m}$ ) Mächtigkeit, von kaffeebrauner Färbung, die - z. T. mit über $2 \mathrm{~m}$ langen schmalen Frostkeilfüllungen - in eine untere mehr gelblichbraune eindringt, die ihrerseits wieder Froststrukturen aufweist. Der liegende Schotter ist teils lose, teils wandsteif, teils verfestigt. Er läßt sich - am Hang des jungpleistozänen Zweigbeckens ausbeißend - über Söhl nach Weng verfolgen. Auch hier wird (in den beiden genannten Kiesgruben) die Verwitterungsrinde bis $2 \frac{1}{2} \mathrm{~m}$ mächtig, und auch der Schotter zeigt die gleiche Ausbildung (speziell hinsichtlich der Verfestigung). Der Anteil an kristallinen Geröllen beträgt $1-4 \%$, im Durchschnitt 2-3\% ; er erscheint nicht hoch, ist aber nicht zu übersehen.

Troll hat diese Vorkommen in seiner Karte $(1: 100000$ des jungdiluvialen Inn-Chiemseegletschers) dem Altdiluvium („Deckenschotter") zugeordnet. Dagegen erheben sich jedoch Bedenken und zwar schon nach den eigenen Angaben Trolls (1924, S. 111), der den altdiluvialen „Deckenschottern" des Westteiles des Inngletschers die gleiche Eigenschaft zuschreibt wie dem Münchener Deckenschotter“, nämlich „den fast völligen Mangel zentralalpiner Gerölle“. Das kann man aber von diesen Schottern in keiner Weise sagen. Dem Kristallinanteil zufolge hätte sie Troll (1924, S. 113) der Rißeiszeit zuordnen müssen. Dagegen spricht wiederum die viel zu starke Verwitterungsrinde sowie ihr allgemeiner Zustand, der in jeder Hinsicht von den nächstgelegenen - und in der Tat fast gänzlich kristallinfreien - „Deckenschottern“ (etwa von Glonn) abweicht.

Auch für dieses Vorkommen verbleibt als Lösung nur: ein mittelpleistozänes, aber ohne Zweifel prä-rißeiszeitliches Alter.

65) So zuerst bei Kraus (1961, S. 53; Bodenverdickung von 1/2 bis auf $3 \mathrm{~m} !)$; dann bei BrunNACKER (1962, S. 125/26); dem hat sich schließlich auch EBERS angeschlossen (1963, S. 87: kaffeebraune Verwitterungszone $\mathrm{n} \mathrm{icht}$ ein anstehender Bodenrest) - entgegen ihrer eigenen, richtigen Beobachtung (1960, S. 67: kaffeebraune, k onkordant a u dem Schot te r hervorge he n d e Verwitterungszone).

66) Kraus (1961) schreibt von diesen ebenso nichts wie von jenen in der orangefarbenen Verwitterungsrinde, obwohl sie schon EBERs (1960, S. 70) ihrer Länge wegen eigens erwähnt hatte

67) Daraus will Kraus (1961, S. 53) schließen, daß der Boden nicht „in situ“ läge.

68) Gewiß war es diese außerordentliche Mächtigkeit, die zuerst Kraus (1961) und danach BrunNaCKer (1962) sowie Ebers (1963) veranlaßt hat, sie durch Solifluktion u. ä. zu erklären. Bei der nicht minder mächtigen (nach Länge der Zapfen sogar noch mächtigeren) orangefarbenen Verwitterung war das aber ganz off ensichtlich nicht mehr möglich. Um so wichtiger wäre es gewesen, sich mit ihr näher zu befassen; sie wurde aber links (sic!) liegen gelassen. 
$\left.\mathrm{Zu} \mathbf{h}^{\prime}\right)$ : Die orangefarbene Verwitterungsrinde ist keineswegs weniger bedeutend als die kaffeebraune. Letztere ist $1-1^{1 / 2} \mathrm{~m}$, in Trichtern und Zapfen bis über $2 \mathrm{~m}$ mächtig ${ }^{69}$ ). Bei der orangefarbenen beträgt zwar die d u r c h g e h e n d e Mächtigkeit (also ohne Zapfen) nur 0,8 bis $1,2 \mathrm{~m}^{70}$ ); das ist aber, wie die scharfe Grenze zum Hangenden zeigt, nicht die ursprüngliche. Auch an der ungewöhnlichen Länge der Verwitterungszapfen (bis $3^{1 / 2} \mathrm{~m}$ !) ist das zu erkennen. Entsprechend dem allgemeinen Verhältnis von durchschnittlicher durchgehender Mächtigkeit der Verwitterungsrinde zur Länge der Verwitterungszapfen (etwa bis $1: 1^{1 / 2}$ ) wird man eine ursprünglich durchgehende Mächtigkeit (also ohne Zapfen) von gut $2 \mathrm{~m}$ annehmen müssen. Danach dürfte es sich bei der orangefarbenen um die mächtigere und entsprechend ältere Verwitterungsrinde handeln. Das wird bestätigt durch die Erscheinung, daß auch außerhalb der eigentlichen Verwitterungsrinde mehr oder weniger zersetzte Geröllpartien auftreten ${ }^{71}$ ), und dem entspricht eine fast durchgehende Verfestigung des zugehörigen Schotters (h). Dieser hat zu allem Überfluß noch die aufgeführte ganz andere Geröllzusammensetzung. Bei ihm ist das Verhältnis von Kalk- u. ä. zu Kristallin- und Quarzgeröllen $50: 48$ bis 62:37, bei dem mit der kaffeebraunen Verwitterungsrinde $66: 34$ bis $68: 31$. Weiterhin ist bemerkenswert, daß sich ihre beiden Verwitterungsrinden nirgends miteinander berühren, sie bleiben voneinander immer in mindestens $70 \mathrm{~m}$ Abstand entfernt.

EBers, die von den bisherigen Bearbeitern den Hörmatinger Aufschluß noch in seinem besten Zustand gesehen hat, beschreibt die orangefarbene („kreßfarbene“) Verwitterungsrinde, geht aber auf sie - außer in der einleitenden Zusammenfassung (= Paudorfer Interstadial) - weiter nicht ein - weder bei ihren "Einzeluntersuchungen“ noch bei ihrer "Deutung des Hörmatinger Profiles" (1960, S. 71 ff. bzw. 74 ff.). Auch in ihrer Erwiderung (1963) auf BrunnaCKer (1962) verteidigt sie gegen dessen Einwände den selbständigen Charakter der orangefarbenen („kreßfarbenen“) Verwitterungszone, gibt ihr aber auch hier keine Deutung. Lediglich aus dem Umstand, daß sie unmittelbar unter der letzteiszeitlichen Grundmoränendecke liegt, die kaffeebraune aber noch unter einem Schotterpaket, möchte EBErs - unter Berufung auf "mehrere Autoren“ (welche?) - die kaffeebraune für älter ansehen (S. 88).

Nun: Abgesehen davon, daß diese Beobachtung nicht überall zutrifft (siehe meine Schichtenfolge bei 3), ließe sich daraus keine Altersfeststellung treffen. Das "Schotterpaket“ von EBERS ist nichts anderes als der "Vorstoßschotter" oder die "Basisfazies" der dazugehörigen hangenden Grundmoräne, also mit ihr gleichen Alters (siehe meine Schichtenfolge bei $1 \mathrm{a}$ und $\mathrm{b}$, sowie $2 \mathrm{a}$ und b).

Kraus (1961, S. 48) legt in seiner Abb. 4 einen Teil der orangefarbenen Verwitterungsrinde u n m it t e l b a r ü b e r die kaffeebraune ("9 = mittelwürminterstadiale Verwitterungsrinde" d. i. sein „Mittelwürmboden“ - über „6 = kaffeebrauner Verwitterungsboden“ - d. i. sein „Altwürmboden“). Im Abb.-Text verlautet, daß „der südliche Grubenteil hauptsächlich nach Angabe von EBERs (1960)“ gezeichnet sei, da er selbst das „tiefere Grubenprofil nicht so vollständig antreffen" konnte (S. 50). Der entsprechenden Darstellung von EBERS (1960, Abb. 2 und 4) ist aber keine Ubereinanderlagerung zu entnehmen. In ihrem Text ist lediglich (in der Zusammenfassung) von einer unteren und oberen Verwitterungsrinde die Rede. Selbst Kraus notiert: „... konnte E. Ebers kürzlich schräg übereinander 2 interstadiale Böden feststellen". Obwohl er das eigens in seinem Text gesperrt bringt, liegen sie aber in seiner Abbildung unmittelbar übereinander! Im Kraus'schen Abb.-Text verlautet vom orangefarbenen Boden: „Auch im S noch etwas fortsetzend"; in seiner Abbildung reicht diese Fortsetzung aber bis zur Mitte der kaffeebraunen Verwitterungsrinde, also fast $120 \mathrm{~m}$ weit! Niemals war das in der bisherigen Abbaugeschichte der Hörmatinger Kiesgrube der Fall. Niemals hat der orangefarbene Boden weiter nach O gereicht als

69) Nach Ebers (1960, S. 67): 2-3 m mächtig werdend; nach Kraus (1961, S. 53): örtlich bis fast $3 \mathrm{~m}$ dick.

70) Nach EbERs (1960, S. 70) „nur 1-11/2 m mächtig“, aber darüberhinaus „greift sie mit langen Zapfen nach unten“. Bei Kraus (1961) fehlt eine diesbezügliche Angabe.

71) Das ist von Brunnacker (1963) richtig beobachtet worden, der im Text (S. 16) von "Anwitterungserscheinungen wie sie in älteren Ablagerungen häufiger vorzukommen pflegen " schreibt und in seiner Abbildung (S. 126) einen "morschen Schotter" einzeichnet. Siehe dazu schon die Anmerkung 29). Wenn im übrigen für EBERs dieser von BrUNNACKER gebrauchte Ausdruck als „ein in der Quartärgeologie nicht eben üblicher Ausdruck" erscheint, so dünkt er mir zutreffender und verständlicher als manche von ihr benutzten Ausdrücke (siehe dazu Anmerkung 8). 
heute und niemals lag ein Teil von ihm ü be $\mathrm{r}$ dem kaffeebraunen. Aber nicht nur in diesem so entscheidenden Punkt ist die Kraus'sche Darstellung falsch. So schreibt er (S. 50), daß in seiner Abbildung „wenigstens die durchschnittlichen Schichtmächtigkeiten im richtigen Maß-Verhältnis erscheinen“. Für die beiden Böden, als die wichtigsten Schichtglieder des Profils, trifft das aber weder nach Mächtigkeit noch Längenerstreckung zu; ebenso nicht für die Höhe: Die kaffeebraune Verwitterung liegt nicht $4-5 \mathrm{~m}$ tiefer als die orangefarbene, sondern fast in der gleichen Höhe. Nachdem schon eine (aus Rosenheim, also über $15 \mathrm{~km}$ Entfernung herbeigeholte) $22 \mathrm{~m}$ lange Feuerwehrleiter zur Verfügung stand, hätte man die tatsächlichen Höhen ohne weiteres ermitteln können.

Kurzum: Auch wenn Kraus (1961, S. 50) schreibt, daß die Zeichnung von Ebers (1960) auf ihren Wunsch in seiner Abb. 4 ergänzt und ins richtige Maßverhältnis gebracht wurde, so ist die sachlich zutreffende Darstellung die von EBERs (1960).

Daß die Art und Mächtigkeit der Verwitterung keinen allgemeinen Altersmaßstab bilden, bedarf hier keiner Erklärung. Wohl aber kann man sie innerhalb eines bestimmten Gebietes von gleichen geographischen Verhältnissen heranziehen und zusammen mit den anderen Gelände- und Aufschlußbefunden zur Altersbestimmung und Parallelisierung nützen. Dann ergibt sich für die beiden mächtigen fossilen Verwitterungsrinden im Hörmatinger Aufschluß ein mittelpleistozänes Alter — und dabei für die orangefarbene ein höheres als für die kaffeebraune ${ }^{72}$ ).

Schotter und Moränen mit ähnlich mächtigen Verwitterungsrinden wurden im Gebiete des pleistozänen östlichen Rheingletschers von Graul bis 1962 der Alt- und Mittelrißeiszeit zugeordnet. In seiner Arbeit von 1962 hat er dann die altrißeiszeitlichen Ablagerungen in der Mehrzahl zur Günzeiszeit, die mittelrißeiszeitlichen zur Mindeleiszeit gestellt. Bei dieser Umgruppierung (vom Mittelins Altpleistozän) ließ er sich vor allem durch die z. T. tief hinabreichende Verwitterung leiten (1962, S. 270).

Wer die von ihm aufgeführten Verwitterungsrinden kennt, dem drängt sich unwillkürlich der Vergleich mit den beiden mächtigen Hörmatinger Böden auf. Auch sie sind älter als nur rißeiszeitlich. Gegen eine Zuordnung ins Altpleistozän (Mindel oder Günz) sprechen jedoch eine Reihe von gewichtigen Gründen. Sie in dieser Arbeit darzulegen, deren Hauptzweck es ist, die Auffassung von einem jungpleistozänen (inner-würmeiszeitlichen) Alter richtig zu stellen, würde zu weit führen.

Bei einem Vergleich mit anderen Bildungen des Mittelpleistozäns im nördlichen Alpenvorland, etwa mit denen im Gebiet des östlichen Rheingletschers, des Iller-Lechgletschers oder des Isar-Loisachgletschers, würde man bis zu einer endgültigen Namensgebung den Schotter mit der orangefarbenen Verwitterungsrinde $\left(h^{\prime}\right)$ zur "Altriß-Eiszeit“ und den mit der kaffeebraunen $\left(\mathrm{g}^{\prime}\right)$ zur „Mittelriß-Eiszeit“ stellen. Die oberste der seinerzeit beobachteten drei fossilen Verwitterungsrinden ( $\left.f^{\prime}\right)$ würde zu einem Schotter der „JungrißEiszeit" gehören.

Einen Vergleich mit anderen pleistozänen Bildungen unternimmt auch Kraus (1960, S. 49/50). Aufgrund bodenchemischer Analysen glaubt er nicht nur eine Ähnlichkeit der beiden mächtigen fossilen Böden untereinander „sehr deutlich" erkennen zu können, sondern meint auch, daß - weit darüber hinaus - „dieselbe Größenordnung der Sesquioxyde im HCl-Auszug der Feinerde, derselbe allgemeine Habitus, dieselbe stratigraphische Lage über denselben Altwürmschotter und unter derselben Hauptwürm-Grundmoräne" zu einer Parallelisierung mit dem Murnauer Boden im W und dem von Paudorf im O hinreichen (S. 50). Zu den letzten zwei Punkten („Habitus“ und Lage) siehe die vorangegangene Richtigstellung. Hier noch zur bodenchemischen Analyse kurz eine Feststellung.

In der folgenden Tabelle sind die Bodenanalysen der „Inner-Würmböden“ von Kraus zusammengestellt, dazu die von meinen Entnahmen sowie, damit überhaupt ein Vergleich möglich wird, solche von jüngeren und älteren Böden. Letzteres hat Kraus, obwohl für eine Altersbestimmung am wichtigsten, ganz außer acht gelassen.

72) In der 1968 erschienenen Heidelberger Dissertation von Metzgen werden neue Wege der bodenchemischen Analyse beschritten, besonders im Hinblick auf eine (relative) Altersbestimmung. Inwieweit sie praktisch genutzt werden können, wird allerdings erst die zukünftige Erprobung zeigen. Die entsprechende Anwendung bei den beiden mächtigen Hörmatinger Böden hat lediglich ein etwas höheres Alter des orangefarbenen gegenüber dem kaffeebraunen erbracht. Ich meine, daß der Altersunterschied größer ist. 
Tabelle 1

Bodenchemische Analysen

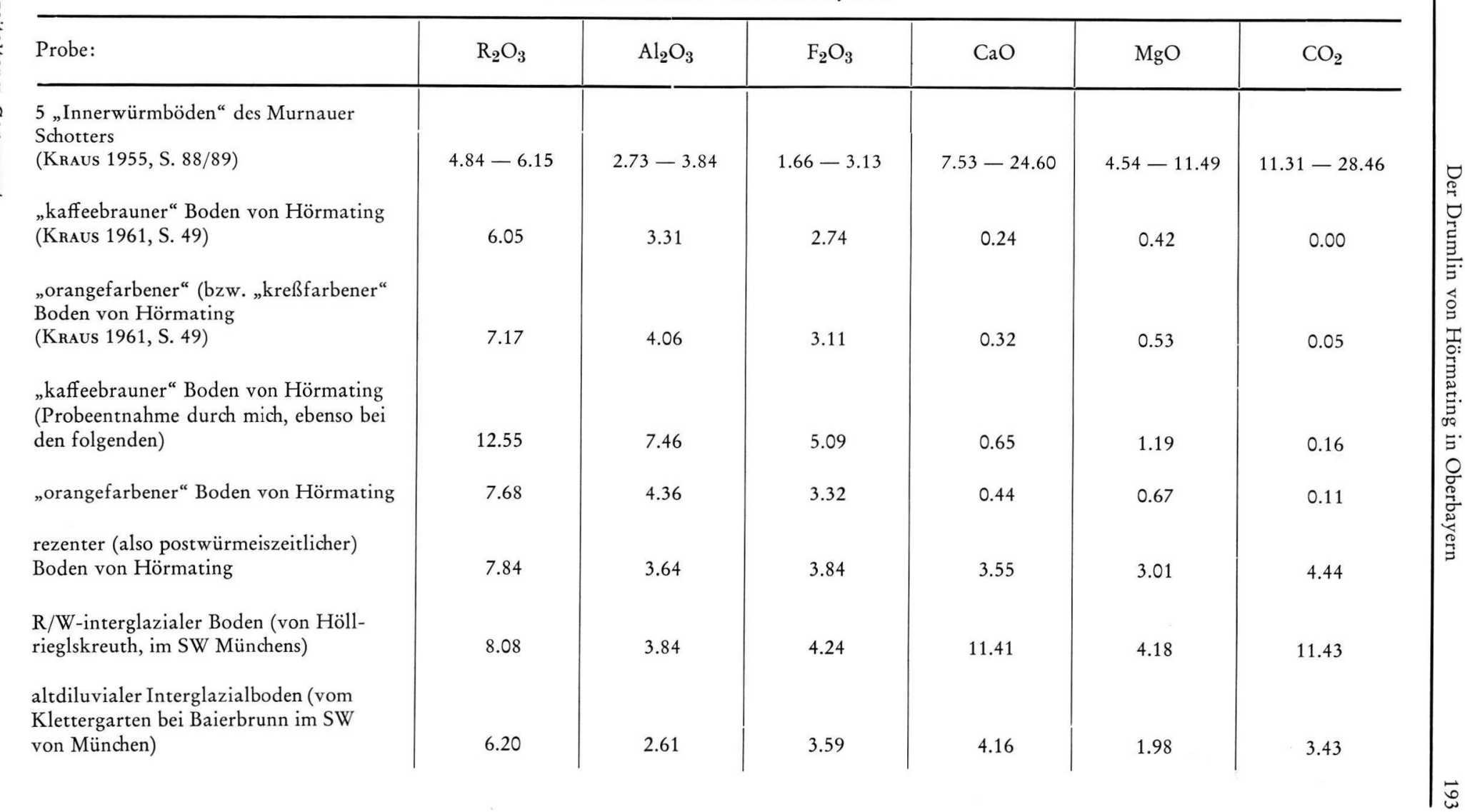


Die von mir (1967) entnommenen Hörmatinger Proben befanden sich - wegen des fortgeschrittenen Abbaues - zwar nicht an derselben Stelle wie die von Kraus, so doch in genau der gleichen Höhenlage und derselben stratigraphischen Situation. Ebenso wurden die Analysen von der gleichen Stelle, der Chemischen Abt. des Bayer. Geol. Landesamtes, durchgeführt.

Worin - zwischen den beiden Hörmatinger Böden, aber auch zu den Kraus'schen Murnauer "Innerwürmböden" - eine Ähnlichkeit bestehen soll, möge der Leser selbst entscheiden. Auch die weiteren von mir angeführten bodenchemischen Analysen zeigen, daß damit eine Parallelisierung ausgeschlossen ist. Man könnte alles mit jedem verbinden, etwa einen ältestpleistozänen mit einem rezenten holozänen Boden. Damit erübrigt sich jedes weitere Eingehen auf dieses Beweismittel von Kraus (1961, S. 49/50).

\section{Ergebnisse:}

1. Von den in der Grube von Hörmating aufgeschlossenen (oder aufgeschlossen gewesenen) Schichten gehört die Grundmoränendecke (a), die sich über verschiedene, teils gleichalte, teils ältere Schichten legt, dem letzten (oder Haupt-)Vorstoß der Würmeiszeit an (W II, etwa 25 / 15000 J.v. h.). - Ebenso in die Würmeiszeit fallen die unmittelbar darunter liegenden fluvioglazialen "Vorstoßschotter" (b), sowie die limnoglazialen Seetone (c). Nicht ausgeschlossen wäre, letztere zum ersten, kleineren würmeiszeitlichen Gletschervorstoß zu stellen (W I, etwa 43 / $35000 \mathrm{~J}$. v. h.).

2. An das Ende des Riß/Würm-Interglazials (oder auch schon in das beginnende Würm-Glazial) gehört die Torfbank (d), deren Alter (nach Radiokarbonmethode) auf $45300 \pm 1000 \mathrm{~J}$.v.h. (bzw. nach darin enthaltenen Holzstücken auf älter als 53000 J. v. h.) bestimmt worden ist, sowie die Seekreide (e), deren Faunen- und Floreninhalt ein temperiertes, etwas kühleres Klima als heute bezeugt.

3. Aller Wahrscheinlichkeit nach spiegelt eine bis $30 \mathrm{~cm}$ mächtige oberste fossile Verwitterungsrinde $\left(\mathrm{f}^{\prime}\right)$, die 1957 im Südwestteil der Grube unter der letzteiszeitlichen Grundmoränendecke sichtbar war, das übrige, eigentliche R/W-Interglazial wieder. Der zugehörige Moränenschotter (f) wäre dann in die Rißeiszeit zu stellen.

4. Alle anderen Schichten des Hörmatinger Aufschlusses fallen in das prä-rißeiszeitliche Mittelpleistozän.

5. Dazu gehört die zweite fossile Verwitterungsrinde $\left(\mathrm{g}^{\prime}\right)$, die kaffeebraune, die sich im Ostteil der Grube findet, mit $1-1^{1 / 2} \mathrm{~m}$ (und in Zapfen bis $2^{1 / 2} \mathrm{~m}$ ) Mächtigkeit, auf einem Schotter (g) entwickelt, der etwa dem entspräche, was - bis zu einer endgültigen Namensgebung - noch mit „Mittelrißeiszeit“ bezeichnet bleiben sollte.

6. Westlich daneben liegt in einem eigenen, gesonderten und älteren Drumlinkern eine dritte fossile Verwitterungsrinde $\left(h^{\prime}\right)$, die orangefarbene, in noch durchgehend $0,8-1,2 \mathrm{~m}$ Mächtigkeit erhalten; das ist aber nur der von dem folgenden Gletscherschurf nicht mehr erfaßte Rest. Von der ursprünglichen außerordentlichen Mächtigkeit zeugen die bis 4,8 m hinabreichenden Verwitterungszapfen, in einem Schotter (h) entwickelt, der altersmäßig etwa dem entspricht, was - bis zu einer endgültigen Namensgebung - noch mit „Altrißeiszeit" bezeichnet bleiben sollte.

Abzulehnen is $\mathrm{t}$,

a) die letzteren beiden fossilen Verwitterungsrinden, die mit zu den mächtigsten gehören, die sich im Pleistozän des Alpenvorlandes finden, als „Interstadialböden“ der Würmeiszeit zu deuten (Ebers 1960, 1963, 1965; Kraus 1961),

b) jeder Zusammenhang mit einem „Paudorfer“- oder „Göttweiger“-Interstadial (EBERS 1960, Gross 1960, Kraus 1961),

c) eine weder stratigraphisch noch geomorphologisch gesicherte Parallelisierung über weite Entfernungen hinweg - etwa mit dem „Laufenschotter“ oder dem „Murnauer Schotter“ (Ebers 1960, Gross 1960, Kraus 1961), 
d) die Annahme eines zeitlich und genetisch zusammengehörigen und geschlossenen „Hörmatinger Seenprofils“, also die Vorstellung, daß der in hohem Maße frostgestörte und glazialgestauchte, im großen ganzen warmzeitliche Seekreide/Torf-Komplex eine Sedimentationseinheit mit dem hangenden, in seinen Lagerungsverhältnissen kaum oder gar nicht gestörten kalt- oder eiszeitlichen Seeton bilde (EBers 1961, 1963),

e) schließlich eine Verbindung der orangefarbenen Verwitterungsrinde mit der kaffeebraunen - also die Auffassung, daß letztere lediglich die hangab gewanderte Solifluktionsmasse der ersteren wäre und daß beide so überaus mächtigen fossilen Verwitterungsrinden in das Riß-Würm-Interglazial gehören (BRUNNACKER 1962).

\section{Schrifttum}

Brunnacker, K.: Bemerkungen zum Profil Hörmating/Obb. - Eiszeitalter u. Gegenwart, 13, 125-128, Ohringen 1962.

EberL, B.: Die Eiszeitenfolge im nördlichen Alpenvorlande. - 427 S., Augsburg 1930.

EвERs, E.: Drumlinkerne, ältere Würmschotter und das Würm-Interstadial-Profil von Hörmating/ Obb. - Eiszeitalter u. Gegenwart, 11, 64-76, Ỏhringen 1960.

- : Kann die begrabene Landoberfläche von Hörmating letztinterglaziales Alter besitzen? - Jb. u. Mitt. Oberrh. Geolog. Ver. N. F. 45, 87-92, Stuttgart 1963.

- : Die Landschaft um Rosenheim (zus. mit E. Kraus), dort Abschnitt III/2: Die Kiesgrube von Hörmating, 212-223, Rosenheim 1965.

Graul, H.: Eine Revision der pleistozänen Stratigraphie des schwäbischen Alpenvorlandes. Pet. Geogr. Mitt., 106, 253-271, Gotha 1962.

Gross, H.: Die bisherigen Ergebnisse von C-14-Messungen und paläontologischen Untersuchungen für die Gliederung und Chronologie des Jungpleistozäns in Mitteleuropa und den Nachbargebieten. - Eiszeitalter u. Gegenwart, 9, 155-187, Öhringen 1958.

- : Die Bedeutung des Göttweiger Interstadials im Ablauf der Würmeiszeit. - Eiszeitalter u. Gegenwart, 11, 99-106, Ohringen 1960.

Höfle, H. Chr.: Ein neues Interstadialvorkommen im Ammergebirgsvorland (Obb.). - Eiszeitalter u. Gegenwart, 20, 111-115, Öhringen 1969.

Knauer, J.: Erl. zu Bl. München-West der Geognostischen Karte von Bayern 1 : 100 000. — München 1929 und 1931.

Kraus, E.: Zur Zweigliederung der südbayerischen Würmeiszeit durch eine Innerwürm-Verwitterungsperiode. - Eiszeitalter u. Gegenwart, 6, 75-95, Ohringen 1955.

- : Die beiden interstadialen Würmböden in Südbayern. - Eiszeitalter u. Gegenwart, 12, 43-59, Ohringen 1961.

Metzger, K.: Phys.-Chemische Untersuchungen an fossilen und rezenten Böden im Nordgebiet des alten Rheingletschers. - Heidelb. Geogr. Arb., 19, 14 Abb., 16 Tab., 99 S., Heidelberg 1968.

PencK, A. \& Brǘckner, E.: Die Alpen im Eiszeitalter. - 1199 S., Leipzig 1901/09.

Reich, H.: Die Vegetationsentwicklung der Interglaziale von Großweil-Ohlstadt und Pfefferbichl im bayerischen Alpenvorland. - Flora oder Allg. Bot. Ztg., 140, 386-443, Jena 1953.

Schaefer, I.: Die Würmeiszeit im Alpenvorland zwischen Riß und Günz. - Abh. Naturwiss. Ver. f. Schwaben u. Neuburg, 2, 148 S., Augsburg 1940.

- : Die diluviale Erosion und Akkumulation, Untersuchungen über die Talbildung im Alpenvorlande. - Forsch. z. dt. Ldskde., 49, 154 S., Landshut 1950.

- : Über methodische Fragen der Eiszeitforschung im Alpenvorland. - Z. deutsch. geol. Ges., 102, 287-310, Stuttgart 1951.

- : Zur Gliederung der Würmeiszeit im Illergebiet. - Geolog. Bavar., 18, 5-9 u. 49-112, München 1953.

TroLl, K.: Der diluviale Inn-Chiemseegletscher, das geographische Bild eines typischen Alpenvorlandgletschers. - Forsch. z. dt. Lds. u. Volkskde., 23, 1-121, Stuttgart 1924.

Wegen der erheblich höheren Druckkosten war es nicht möglich, Buntbilder von den mächtigen mittelpleistozänen Verwitterungsrinden mit ihren eindrucksvollen Verwitterungszapfen beizulegen. Den von meinen Ausführungen betroffenen Autoren werde ich aber Buntfotos zusenden, ebenso jenen an dieser Frage interessierten Lesern, die dies eigens wünschen.

Manuskr. eingeg. 29. 5. 1968.

Anschrift des Verf.: Ingo Schaefer, Dr. rer. nat., Prof., 8032 Gräfelfing bei München, Maria-EichStraße 120. 